\title{
Color Processing in Zebrafish Retina
}

\author{
April Meier ${ }^{1}$, Ralph Nelson ${ }^{2}$ and Victoria P. Connaughton ${ }^{1 *}$ \\ 'Zebrafish Ecotoxicology, Neuropharmacology, and Vision Lab, Department of Biology, and Center for Behavioral \\ Neuroscience, American University, Washington, DC, United States, ${ }^{2}$ Neural Circuits Unit, National Institute of Neurological \\ Disorders and Stroke (NINDS), NIH, Bethesda, MD, United States
}

Zebrafish (Danio rerio) is a model organism for vertebrate developmental processes and, through a variety of mutant and transgenic lines, various diseases and their complications. Some of these diseases relate to proper function of the visual system. In the US, the National Eye Institute indicates >140 million people over the age of 40 have some form of visual impairment. The causes of the impairments range from refractive error to cataract, diabetic retinopathy and glaucoma, plus heritable diseases such as retinitis pigmentosa and color vision deficits. Most impairments directly affect the retina, the nervous tissue at the back of the eye. Zebrafish with long or short-wavelength color blindness, altered retinal anatomy due to hyperglycemia, high intraocular pressure, and reduced pigment epithelium are all used, and directly applicable, to study how these symptoms affect visual function. However, many published reports describe only molecular/anatomical/structural changes or behavioral deficits. Recent work in zebrafish has documented physiological responses of the different cell types to colored (spectral) light stimuli, indicating a complex level of information processing and color vision in this species. The purpose of this review article is to consolidate published morphological and physiological data from different cells to describe how zebrafish retina is capable of complex visual processing. This information is compared to findings in other vertebrates and relevance to disorders affecting color processing is discussed.

Edited by: Philippe Isope, Centre National de la Recherche Scientifique (CNRS), France

Reviewed by: Susan E. Brockerhoff, University of Washington, United States Elvir Becirovic, Ludwig-Maximilians-Universität München, Germany

${ }^{*}$ Correspondence: Victoria P. Connaughton vconn@american.edu

Received: 18 July 2018 Accepted: 10 September 2018 Published: 03 October 2018

Citation:

Meier $A$, Nelson $R$ and Connaughton VP (2018) Color Processing in Zebrafish Retina. Front. Cell. Neurosci. 12:327. doi: 10.3389/fncel.2018.00327
Keywords: Danio rerio, color vision, red, green, blue, ultraviolet

\section{ZEBRAFISH RETINAL STRUCTURE AND DEVELOPMENT}

Zebrafish retina, like those of other vertebrates, contains five neural types organized into layers. Distal-most are photoreceptors (PRs) with cell bodies in the outer nuclear layer (ONL) and terminals forming synaptic contacts with the dendritic processes of bipolar (BCs) and horizontal (HCs) cells in the outer plexiform layer (OPL). The cell bodies of these second order neurons, as well as those of third order amacrine cells (ACs), reside in the inner nuclear layer (INL). BCs are presynaptic to $\mathrm{AC}$ and ganglion cell (GC) dendrites in the inner plexiform layer (IPL), where processes in the distal IPL, or sublamina $a$, mediate OFF-type responses and processes in sublamina $b$ mediate ON-type responses. GC bodies are in the most proximal layer, the GC layer (GCL).

\section{Development of Neurons and Circuits}

Eye morphogenesis in zebrafish begins at $12 \mathrm{~h}$ postfertilization (hpf; Schmitt and Dowling, 1994). Subsequent structural changes to eye primordia result in well-formed optic cups at $24 \mathrm{hpf}$ (Schmitt and Dowling, 1994), and development of the neural retina progresses in direction from the inner (vitreal) to the outer (scleral) retina. GC and AC form first $(\sim 32 \mathrm{hpf})$, with a small number of GC axons leaving the eye to form the optic nerve at 
〜34-36 hpf (Stuermer, 1988; Schmitt and Dowling, 1994, 1999; Burrill and Easter, 1995). Initial differentiation of PRs occurs in a patch ventral to the optic nerve head at $\sim 50 \mathrm{hpf}$ (Kljavin, 1987; Raymond et al., 1995; Hu and Easter, 1999; Schmitt and Dowling, 1999; Raymond and Barthel, 2004). Development in the patch continues in advance of other retinal regions until $\sim 70 \mathrm{hpf}$, when the entire retina appears homogeneous. BC are the last cell type to form at $\sim 60 \mathrm{hpf}$ (Schmitt and Dowling, 1999) and between 60-70 hpf all neuronal cell types can be identified and synapses are apparent (Schmitt and Dowling, 1999). The vertical pathway (i.e., PR-to-BC-to-GC) appears functional at 70-74 hpf (Schmitt and Dowling, 1999), corresponding to innervation of the optic tectum (Stuermer, 1988), hatching, and the onset of visually guided behaviors (Easter and Nicola, 1996, 1997). Many of the developmental transcription factors such as cone rod homeobox gene ( $c r x$ ), atonal (ath5) and thyroxin $\beta 2$ nuclear receptor $(\operatorname{tr} \beta 2)$, which are key to retinal development in mammals, also operate in zebrafish retina (Kay et al., 2001; Shen and Raymond, 2004; Jusuf et al., 2011; Suzuki et al., 2013).

\section{Development of Electrical Signals}

Physiological studies show cone inputs dominate electroretinogram (ERG) responses in zebrafish larvae younger than days postfertilization (15 dpf; Bilotta et al., 2001) and recordings from larval GC already reveal complex cone-opponent spectral responses (Connaughton and Nelson, 2015). Rod PR density is low in larvae younger than $10 \mathrm{dpf}$ (Fadool, 2003), explaining the cone-dominated electrical activity of the larval eye. Increased rod outer segment length and synaptic connections occur between $12 \mathrm{dpf}$ and $15 \mathrm{dpf}$ (Branchek and Bremiller, 1984) resulting in an increase in sensitivity (Branchek, 1984). However, the retina does not appear adult-like until after $20 \mathrm{dpf}$ (Branchek and Bremiller, 1984) at which time both rod and cone responses can be detected in the zebrafish ERG (Bilotta et al., 2001). The early development of cones, and later development of rods, is also characteristic of mammalian retinas (Carter-Dawson and Lavail, 1979).

\section{CONE PHOTORECEPTORS ALLOW DETECTION OF LIGHT RANGING FROM LONG (RED) TO ULTRAVIOLET (UV) WAVELENGTHS}

\section{Opsins and Cone Morphology}

Zebrafish possess four morphological cone types as well as rods. The cones cover an even broader range of the optical spectrum than do human cones. In adults, the cones are classified as short single cones, long single cones, and a double cone pair based on morphology (Engström, 1960), opsin expression, and relative peak absorption wavelengths $(\lambda \max )$. Short single cones have a $\lambda \max \sim 360 \mathrm{~nm}$; these are the ultraviolet (UV)-sensitive cones (SWS1 opsin). Long single cones are short wavelength sensitive (SWS2 or blue opsin) cones with a $\lambda \max \sim 415 \mathrm{~nm}$. Double cones include an accessory member, the middle wavelength sensitive (MWS or green) cone, with a $\lambda \max \sim 480 \mathrm{~nm}$ (probably green opsin RH2-2), and a principal member, the long wavelength sensitive (LWS1 or adult red opsin) cone, with a $\lambda \max \sim 570 \mathrm{~nm}$ (Nawrocki, 1985; Robinson et al., 1993; Cameron, 2002; Chinen et al., 2003; Allison et al., 2004; Endeman et al., 2013). Molecular analysis of opsin expression in these different cone types has identified two genes encoding the opsins in red cones, four genes for green opsins, and a single gene each for the blue and UV opsins (Chinen et al., 2003).

Within each PR outer segment, a chromophore (11-cisretinal) binds to an opsin molecule forming the visual pigment complex that absorbs light photons (Hubbard and Kropf, 1958). There are two forms of retinal, derived from either vitamin A1 or A2 (Saari, 2012). Zebrafish use only vitamin A1 based pigments, unless they are experimentally treated with thyroxine, which induces the synthesis of vitamin A2 (Allison et al., 2004; Enright et al., 2015).

\section{Cone Mosaics in Larvae and Adults}

The four cone types allow zebrafish to respond to wavelengths of light ranging from UV to red. In adults (Figure 1), the cones are organized into a row mosaic (Allison et al., 2010) in which double cones alternate with single cones such that the red cone is always adjacent to a blue cone and the green cone is always adjacent to a UV cone (Engström, 1960; Larison and Bremiller, 1990; Raymond et al., 1993; Allison et al., 2010). This row mosaic, first described by Engström (1960), supports a two Red: two Green: one Blue: one UV cone ratio that is constant over the entire retina, except for a small primordial region (Allison et al., 2010). Rod PRs insert into this cone mosaic, with four rods forming a square around each UV cone (Fadool, 2003; Morris and Fadool, 2005). When the retina is viewed in cross-section, it is evident that rods and cones do not form a single row but organize into tiers within the PR layer. The nuclei of short single UV cones are located most proximally. Moving distally one next identifies nuclei of long single blue cones, and then the double cones. Rod nuclei are located proximal to short single cones, while their outer segments are distal to double cones (Branchek and Bremiller, 1984; Robinson et al., 1993).

In contrast to adults, the cone mosaic in larval zebrafish (Larison and Bremiller, 1990) is less well organized and heterotypic, with regularly spaced PRs, but no row pattern (Allison et al., 2010). UV cones form first (Raymond et al., 1995;

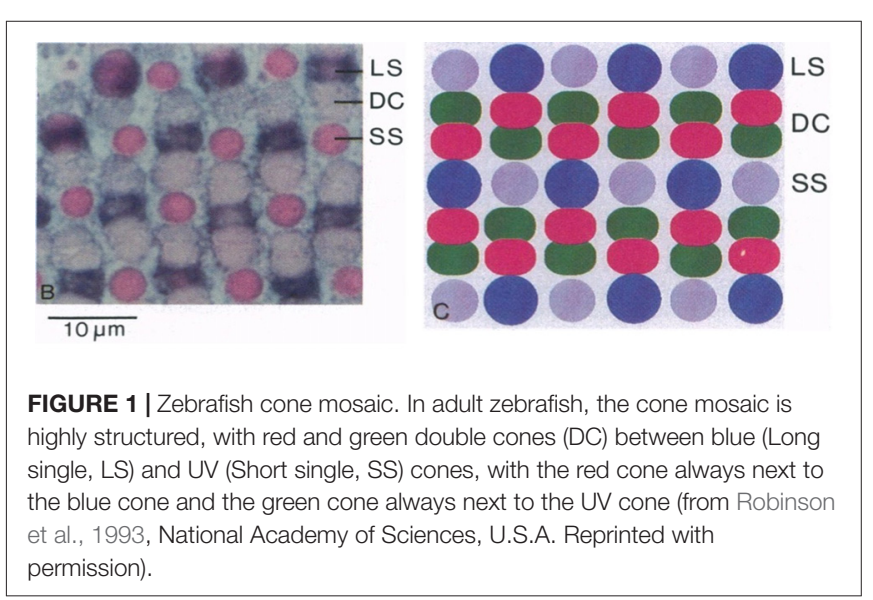


Robinson et al., 1995; Schmitt and Dowling, 1999) and are most abundant in larval retina, followed by blue cones. Red/green double cones form last (Robinson et al., 1995; Schmitt and Dowling, 1999) and are least abundant (Allison et al., 2010). Interestingly, opsin expression displays the opposite pattern with expression of red and blue opsins occurring several hours before expression of UV opsin (Schmitt and Dowling, 1999). Red and blue opsins occur in a tandem genetic pattern under a single promoter (Chinen et al., 2003), as do the four variants of green opsins. In cone types with multiple opsin genes (i.e., red and green cones), in situ hybridization identified sequential expression of these opsin genes during development (Takechi and Kawamura, 2005). It is the shorter-wavelength-peaking LWS2 that is mainly expressed in larvae, while adults express a mixture of LWS1 and LWS2. For green opsins, the shorterwavelength-peaking RH2-1 is earliest expressed, followed by the longer-wavelength-peaking RH2-2, RH2-3 and RH2-4. After the cone mosaic is present, the rod mosaic forms (Fadool, 2003; Morris and Fadool, 2005). Transition from larval to the adult mosaic occurs during the postlarval/juvenile period when the fish are $>3$ weeks of age (Allison et al., 2010).

\section{OUTER RETINA-PROCESSING OF COLOR SIGNALS AT THE FIRST RETINAL SYNAPSE}

Processing of color signals from different PRs occurs in outer retina. $\mathrm{BCs}$ are morphologically diverse retinal interneurons that receive combinations of inputs from rods and different cone types. Zebrafish HCs similarly contact specific combinations of $\mathrm{PR}$ types resulting in mono- and multiphasic spectral response properties that in total reflect inputs from all four cone types. PR inputs to BCs are modified by feedforward and feedback synapses from these spectrally-coded HCs, resulting in significant color processing at this first retinal synapse.

\section{Vertebrate HCs}

Mammalian retinas have, in general, two morphological HC types. A-cells are axonless, and large in dendritic extent; whereas the dendritic fields of B-cells are smaller and an axon ending in a terminal arbor projects from the cell body (Fisher and Boycott, 1974). Primate and rodent retinas are exceptions to the mammalian pattern. In primates, $\mathrm{HI} \mathrm{HCs}$ are similar to B-cells, HII HCs are similar to A-cells, but HIII HCs more resemble teleost HCs, with a long "axon" without terminal arborization projecting from the cell body (Ahnelt and Kolb, 1994; Dacey et al., 1996, 2000). In rodents, there is only a single, B-type HC morphology (Peichl and González-Soreiano, 1994). In teleosts, all HC types bear an axon lacking terminal arborization. There are four HC morphologies in teleosts: $\mathrm{H} 1-\mathrm{H} 4$. Types $\mathrm{H} 1-\mathrm{H} 3$ are postsynaptic to cone PRs, while H4, the rod horizontal cell (HC), is postsynaptic only to rods (Stell and Lightfoot, 1975; Stell, 1975; Weiler, 1978).

In vertebrates, each $\mathrm{HC}$ type receives input from specific numbers and types of PRs resulting in either spectrally monophasic (L-type) or multiphasic (C-type responses; Nelson, 1977; Yang et al., 1983; Siminoff, 1986; Djamgoz et al., 1988;

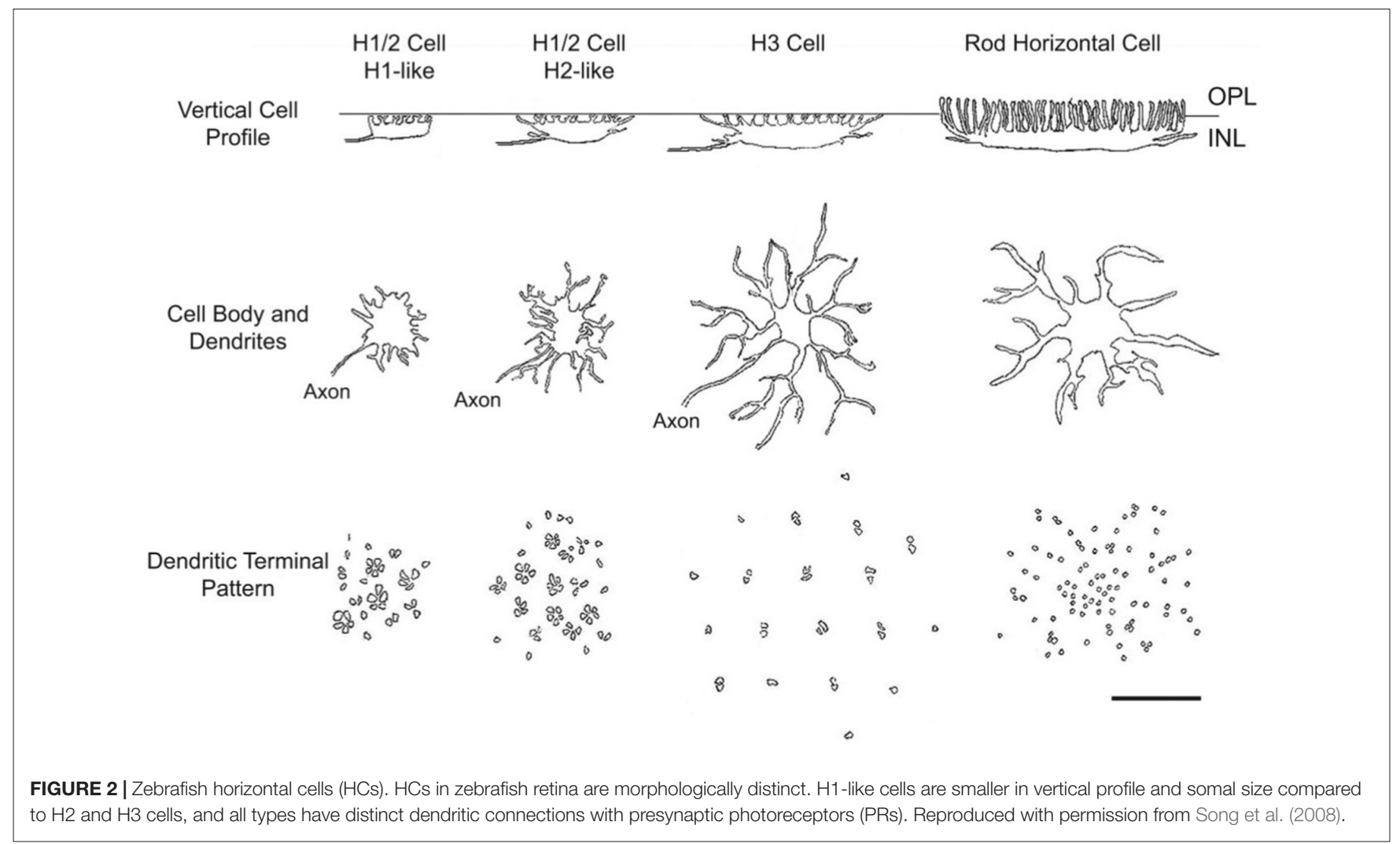


Negishi et al., 1988; Dacey et al., 1996, 2000; Asi and Perlman, 1998; Twig and Perlman, 2004; Yin et al., 2006). One conspicuous difference in the physiology of mammalian HCs as compared to other vertebrates is the complete lack of C-type responses.

\section{Cone Contacts of Horizontal Cell Types}

Zebrafish HC contribute to color vision by facilitating coloropponent mechanisms through feedback and feedforward connections to PR and/or BC (Song et al., 2008). As in goldfish (Stell, 1967; Stell and Lightfoot, 1975), zebrafish cone-contacting $\mathrm{HCs}$ are morphologically characterized as $\mathrm{H} 1, \mathrm{H} 2$, or $\mathrm{H} 3$ types, and rod horizontal cells (RHCs or H4 type) which contact rods (Song et al., 2008; Li et al., 2009). All zebrafish HC are axonbearing, with a snake-like terminal that does not contact PRs running within the OPL (Song et al., 2008).

Zebrafish H1 HC (Figure 2) have a plate-shaped soma from which short dendritic processes protrude. H2 HC exhibit a wider profile than $\mathrm{H} 1 \mathrm{HC}$ and have an ellipsoid soma that extends tendril-like dendritic processes. The dendritic terminals of $\mathrm{H} 1$ and $\mathrm{H} 2$ occur in clusters of 5-6 boutons arranged in a rosette. The rosettes contact both double and single cone rows.
When overlapped onto this cone mosaic, patterns consistent with contacts between HCs and either red, green and blue cones (H1 cells) or green, blue and UV cones (H2 cells) appear ( $\mathrm{Li}$ et al., 2009). Due to H1/2 cell partial clusters and in some cases single boutons, it is probable certain individual cones may make connections with more than one $\mathrm{HC}$. The remaining elements of the cluster would be contacted by another HC. H3 HC have an elongated cell body, with 3-4 long dendritic processes terminating in a rhomboid pattern with boutons arranged in doublets (Connaughton et al., 2004; Song et al., 2008). The dendritic extent of $\mathrm{H} 3$ is distinctly wider than either $\mathrm{H} 1$ or $\mathrm{H} 2$, making it easily recognizable. Examination of the $\mathrm{H} 3$ dendritic pattern on a transgenic cone mosaic where UV cone terminals are labeled suggests $\mathrm{H} 3$ cells selectively contact long single blue and/or short single UV cones, a pattern appearing to serve short wavelengths (Song et al., 2008; Li et al., 2009).

\section{Development of H3 Types}

The development of $\mathrm{H} 3$ cells was followed in larval zebrafish where the ratio of UV to blue cone synapses increased from about $2: 1$ at $3 \mathrm{dpf}$ to $5: 1$ at $10 \mathrm{dpf}$. This ratio is greater than
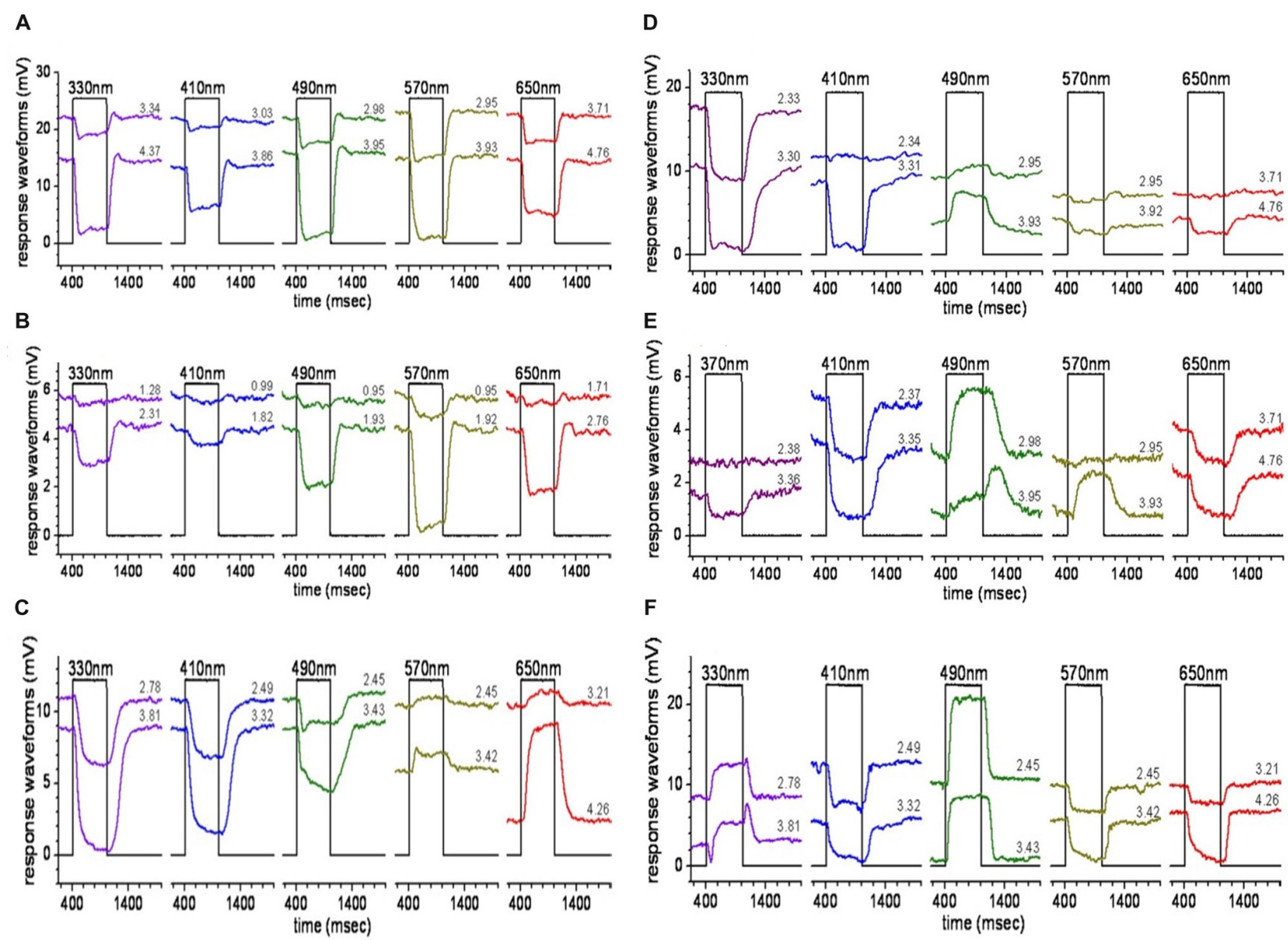

FIGURE 3 | HC responses. Stimulation of zebrafish eyecups with light of different spectral wavelengths evokes different responses from zebrafish HCs. (A,B) H1-type cells hyperpolarize to all wavelengths, giving an L-type response; while (C) H2 cells are biphasic, hyperpolarizing to G, B, and ultraviolet (UV) and depolarizing to R light. H3-type HCs, in contrast, display triphasic (D,E) and tetraphasic (F) responses to spectral stimuli (from Connaughton and Nelson, 2010). 
the ratio of UV to blue cones, suggesting $\mathrm{H} 3$ cells actively seek out contacts with UV cones during development. The $\operatorname{tr} \beta 2$ nuclear receptor is required for red cone development (Ng et al., 2001; Suzuki et al., 2013). When the density of UV cones was increased (and red cones decreased) by suppression of $\operatorname{tr} \beta 2$ nuclear receptor, $\mathrm{H} 3$ dendrites grew and accommodated the extra UV cells with synapses. Genetic suppression of blue or UV synaptic transmission suggested that, at least for the UV to $\mathrm{H} 3$ synapse, activity is critical for synapse formation (Yoshimatsu et al., 2014).

\section{Horizontal Cell Spectral Processing}

Intracellular recordings of $\mathrm{HC}$ spectral responses identified luminosity (L-type) and chromaticity (C-type) HCs (Connaughton and Nelson, 2010), as in other teleosts (Svaetichin and Macnichol, 1958), including other cyprinidae (Naka and Rushton, 1966a,b; Kaneko, 1970). L-type, or spectrally monophasic responses hyperpolarize to light at all stimulus wavelengths and irradiances (Figures 3A,B). Most zebrafish HCs encountered $(\sim 66 \%)$ were L-type. Of these L-type responses, the majority were red-preferring L2 cells, with peak sensitivity to wavelengths $\sim 560 \mathrm{~nm}$; the rest are red/green L1 cells with a mean peak sensitivity $\sim 490 \mathrm{~nm}$ (Connaughton and Nelson, 2010). C-type responses included spectrally biphasic, triphasic, and tetraphasic varieties. Biphasic cells depolarized to long wavelength stimulation $(>570 \mathrm{~nm})$ but hyperpolarized to wavelengths $\leq 530 \mathrm{~nm}$ (Figure 3C). Spectral responses of triphasic cells, in general, hyperpolarized to long wavelength stimuli $(650,610$, and $570 \mathrm{~nm})$, and depolarized to middle and short wavelengths (530, 490, and $450 \mathrm{~nm}$ ). UV triphasic cells hyperpolarized strongly to 370 and $330 \mathrm{~nm}$ stimuli, while blue triphasic cells hyperpolarized weakly to these UV stimuli, but more strongly to a $410 \mathrm{~nm}$ stimulus (Figures 3D,E). The final HC spectral response identified was a unique tetraphasic response (Figure 3F) characterized by hyperpolarization to red-yellow (650-570 nm), depolarization to green and green-blue (530, $490 \mathrm{~nm}$ ), hyperpolarization to 450,410 and/or $370 \mathrm{~nm}$, and depolarization to UV (330 nm; Connaughton and Nelson, 2010). Dye fills of recorded cells indicate HCs with L-type and biphasic spectral responses were similar in morphology (Connaughton and Nelson, 2010) and distinct from cells with triphasic and tetraphasic responses. Combining images of microelectrode stains and response properties with the anatomical studies of HC morphologies and PR terminals (Li et al., 2009), suggests: (a) L-type responses occur in H1 HCs; (b) biphasic cells are $\mathrm{H} 2$ cells; and (c) triphasic and tetraphasic responses occur in H3-type HC (Li et al., 2009; Connaughton and Nelson, 2010).

\section{CONE SYNAPSES WITH BIPOLAR CELLS}

\section{Vertebrate BCs Are Similar in Glutamatergic Mechanisms and Axonal Stratification Patterns}

Zebrafish BCs were initially classified by their glutamate-gated currents, which identified both ON- and OFF-type cells. ON-cells express metabotropic glutamate receptors and a chloride channel forming glutamate transporter on their dendritic arbor (Grant and Dowling, 1995); whereas, OFF-type cells express AMPA/kainate receptors (Connaughton and Nelson, 2000). The ON-BC dendritic "glutamate transporter channel" is not seen in mammals as it provides presynaptic inhibition on axon

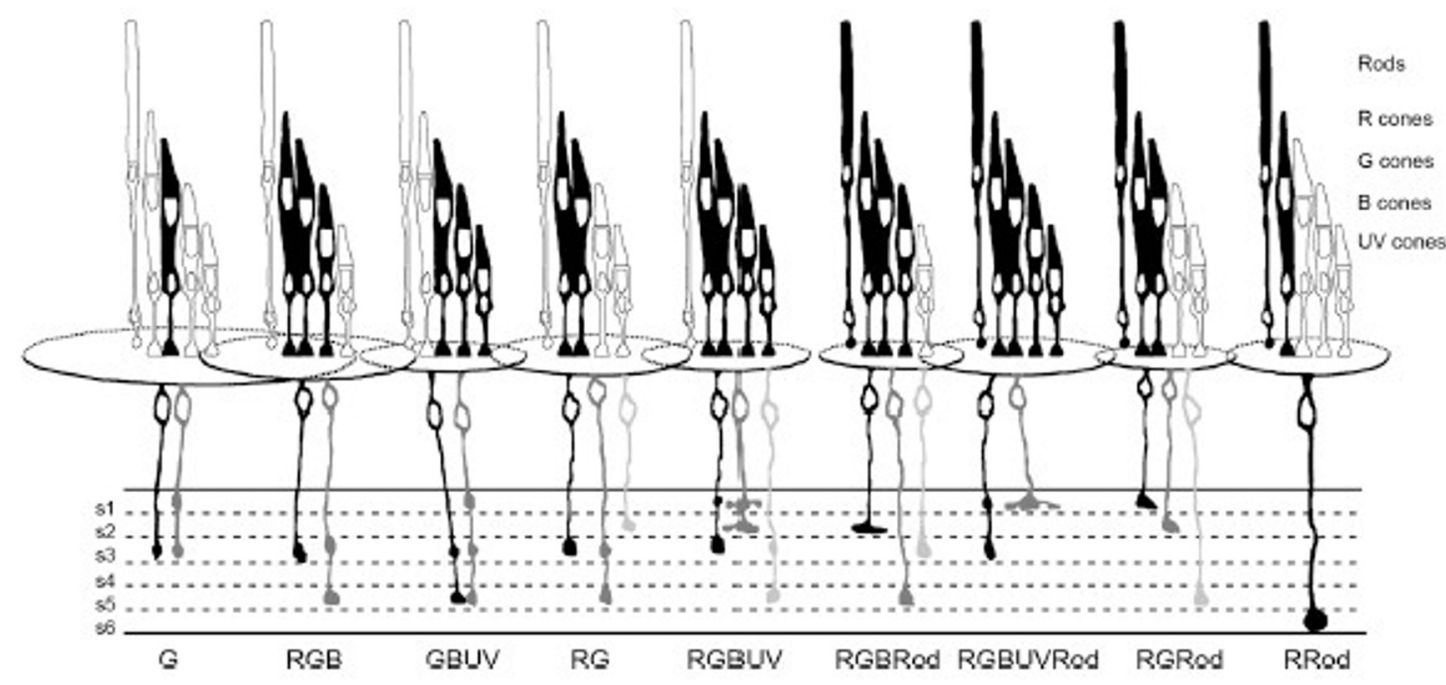

FIGURE 4 | Bipolar cells make diverse connections with PRs. Summary figure (reproduced with permission from Li et al., 2012) showing the different PR connections associated with morphologically-distinct types of BCs. Each BC was identified by axon terminal ramification within the six sublaminae (s1-s6) of the inner plexiform layer (IPL) and by dendritic connections with specific cone types. Most BC types make connections with multiple (>2) PR types, except for two types that exclusively contact green cones (at left of figure) Rod, contacts rods; R, red cones; G, green cones; B, blue cones; UV, UV cones. Shading reflects frequency of identification of a given type, with the darker (black) color indicating the most commonly observed type. 
terminals of mammalian ON-type BCs (Wersinger et al., 2006). Morphologically, the axon terminals of physiologically ON-BCs were found within IPL sublamina $b$ while OFF-BC terminals were in sublamina $a$ (Connaughton and Nelson, 2000). These sublamina divide the IPL roughly in half, with sublamina $a$ represented by the outer half, near ACs, and sublamina $b$ by the inner half, near GCs, consistent with IPL structure and BC morphology in other vertebrates. Subsequent studies using dye-labeling methods (DiI) introduced a 6-stratum scheme for classifying bipolar axon terminal depth within the zebrafish IPL and identified $\sim 17$ morphological types of BCs based on axonal stratification patterns (Connaughton et al., 2004; Li et al., 2012). This number of types was large as compared to mammals (Kolb et al., 1981; Haverkamp et al., 2005; Masland, 2012) and amphibians ( $\mathrm{Wu}$ et al., 2000), but similar to the 15 types identified in goldfish with Golgi staining (Sherry and Yazulla, 1993). Of the 17 types in zebrafish, $\sim 7$ were OFFcells, $\sim 6$ were ON-cells, and $\sim 4$ were presumed ON-OFF cells with axon terminals in both sublamina $a$ and $b$ (Connaughton et al., 2004). This latter type, with bistratified axon terminals, physiologically expressed either OFF-type or ON-type glutamate receptors (Connaughton and Nelson, 2000).

\section{Bipolar Cells Differentially Contact Multiple Cone Types}

Superposition of DiI-stained BC dendrites onto the zebrafish cone mosaic revealed BC type-specific synaptic connection patterns with PRs, and further expanded the number of $\mathrm{BC}$ types to $\sim 33$ (Li et al., 2012). Nine dominant patterns of PR connections accounted for $96 \%$ of a total of 18 patterns found (Figure 4). These dominant patterns included both cone-only $\mathrm{BCs}$, exclusively postsynaptic to cone PRs, and mixed-rod-cone input BCs ( $\mathrm{Li}$ et al., 2012). Only one of the cone-selective patterns was restricted to a single cone type (green cones), and one of the mixed rod-cone patterns received input from all PR types. Examining the axon-terminal stratification types among these PR connectivity patterns, six of the nine patterns included monostratified ON types, with terminals in s4-s6 and either monostratified or bistratified OFF types, with all terminals in s1-s3. Four of the patterns included ON-OFF axon terminal stratification types. The variety in presynaptic connections, the dendritic field size of each $\mathrm{BC}$, and the terminal ramification patterns in the IPL (Li et al., 2012) suggest selective and elaborate color circuits involving $\mathrm{BCs}$ across the entire retina.

\section{Bipolar Cell Spectral Properties}

Recent calcium-imaging 2-photon microscopy of BC axon terminals in live zebrafish larvae found BCs that were chromatic (wavelength selective), achromatic (responding to all wavelengths), or opponent (opposite responses at two wavelengths; Figure 5). To image light-driven calcium activity, a transgene, consisting of the ribeyeA/ctbp 2 promoter, which is selectively expressed by retinal BCs, and the synaptophysin-GCaMP6f fusion protein, a synaptically localized calcium sensor (Dreosti et al., 2009; Zimmermann et al., 2018), was inserted into the zebrafish genome.

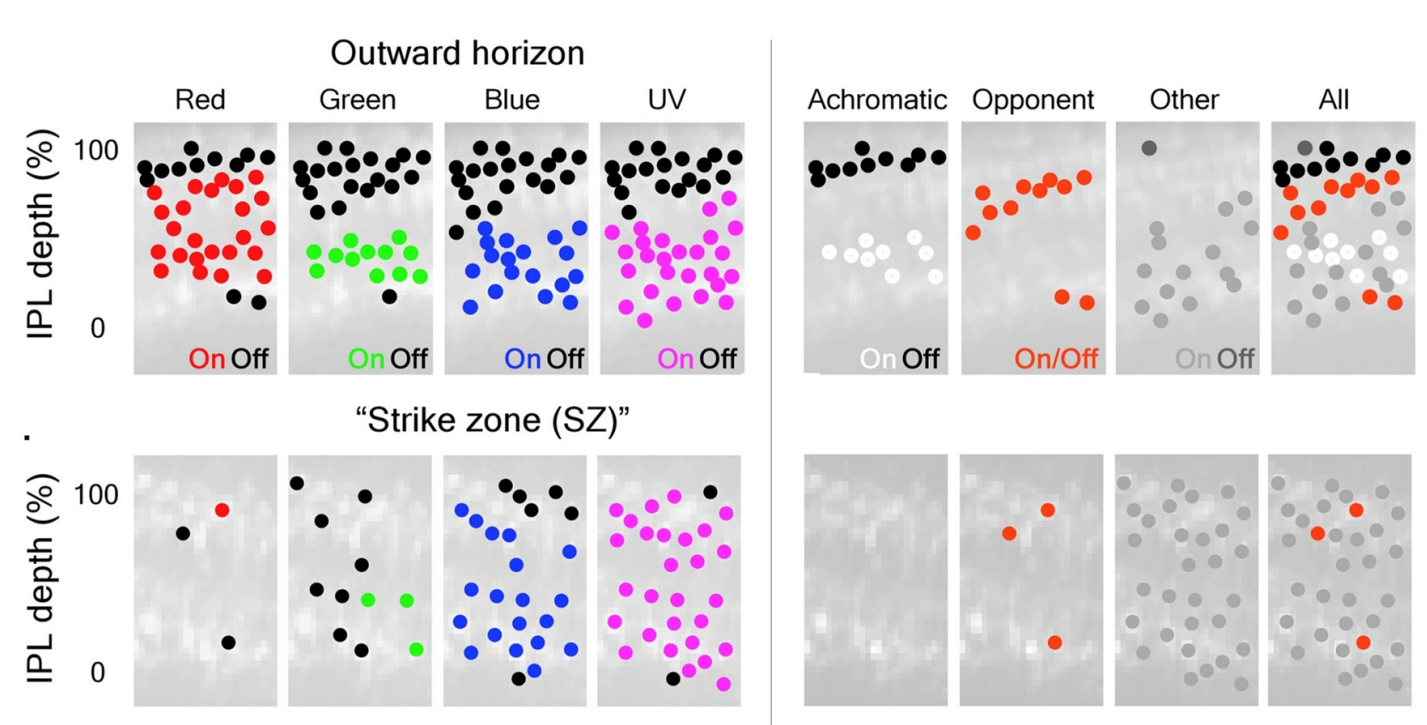

FIGURE 5 | Color inputs to inner retina are segregated in the IPL. BC terminals in the larval zebrafish IPL can be segregated based on the spectral inputs they respond to across the visual scene. (Left) BC-terminal excitation by R, G, B, and UV stimuli are represented as red, green, blue and magenta dots located throughout the IPL; inhibitory responses are represented as black dots. The distribution of ON-responses varies based on the spectral stimulus and which part of the visual scene (outer horizon vs. "strike zone (SZ)") is being viewed. The "SZ" represents looking forward and upward at prey items. (Right) Subsequent classification of the different spectral inputs from BCs into the IPL identified achromatic and color-opponent regions in this synaptic layer that were most evident outside the "SZ". For the right panels: black dots = achromatic OFF-responses, white dots = achromatic ON-responses, red dots = color-opponent responses, gray dots = "other" (taken from Figure 3, Zimmermann et al., 2018). 
A blue-UV chromatic response was found to be regionally selective, with a preponderance of ON-type UV-excited BC terminals throughout the IPL. In retinal topology, these cells densely occupy a temporal-ventral "strike zone (SZ)," the region looking forward and upward at prey (Zimmermann et al., 2018). Both ON and OFF achromatic types responded with excitation or inhibition to all wavelengths tested. Opponent responses included red excited, green, blue and UV inhibited, as well as blue and UV excited, but red, green inhibited. These results are broadly consistent with neuroanatomical connectivity of BCs, particularly in respect to the many cone signals represented in $\mathrm{BC}$ terminals throughout the depth of the IPL, which attests to the idea that multi-cone contacting BCs may connect to cones in a color-opponent manner.

To date, there have been no studies reporting the spectral responses of zebrafish BCs using either whole-cell patch or sharp electrode techniques. In the closely related Giant Danio retina (Danio aequipinnatus), however, patch recordings of bistratified cone BCs with axonal boutons in both sublamina $a$ and sublamina $b$ (Cab BCs) revealed color-opponent responses, excited by one wavelength, but inhibited by another. The Cab cells subtract signals from cones with different opsin expression, and multiple spectral patterns were observed. There was evidence that different types of $\mathrm{BC}$ dendritic glutamate receptors were stimulated by different spectral types of cone (Wong and Dowling, 2005). Further, spectral light stimulation (red, green, or blue), evoked double color-opponent responses. Selectively blocking AMPA/kainate receptors or glutamate transporter associated chloride channels on these cells revealed that the responses to stimulation with short and long wavelengths are mediated by these two-different glutamate-gated mechanisms (Wong and Dowling, 2005).

\section{ERG b-Waves Suggest Bipolar-Cell Spectral Properties}

The ERG is a light-evoked retinal field potential that sums activities of retinal neurons. ERG b- and d-waves represent, and are dominated by, the massed activity of $\mathrm{ON}$ - and OFF-BC types in zebrafish, respectively. The b-wave in adult zebrafish receives contributions from all four cone types and exhibits evidence of red-green color-opponent mechanisms (Hughes et al., 1998). Modeling these inputs, (Cameron, 2002) separated b-wave signals into four different processing channels, one for each cone type. Two color channels (long and middle wavelengths) were involved in color-opponent processing, while the short and UV wavelength channels were not (Cameron, 2002). This suggests BCs detect wavelengthdependent differences in both chromatic and luminance contrast (Cameron, 2002).

ERG b-wave responses in larval zebrafish are different from those in adults. Adult ERG responses include a-wave, b-wave, and d-wave components at all stimulus wavelengths and irradiance levels (Bilotta et al., 2005). The components present in a larval ERG, however, are wavelength dependent. For example, in response to UV light stimulation, the larval ERG includes a large a-wave, delayed b-wave, and small/no d-wave. However, if middle/long wavelength stimuli are used, the ERG has a small/no a-wave followed by large amplitude b- and d-waves (Bilotta et al., 2005). The ERG of larval zebrafish retina is dominated by UV cones, and the physiological differences in a-wave amplitude evoked using UV vs. longer wavelength stimuli can be attributed to differences in cone representation in larval responses (Bilotta et al., 2005). However, differences in larval b-wave (ON-BC) responses may also be due to differences in glutamate receptor expression on these cells. For example, UV and short wavelength stimuli seemed to be mediated by APB-sensitive metabotropic glutamate receptors on $\mathrm{ON}-\mathrm{BC}$ dendrites, while longer wavelength stimuli were not (Bilotta et al., 2005). Multiple glutamategated mechanisms are present on adult zebrafish ON-BCs (Connaughton and Nelson, 2000; Nelson and Singla, 2009) and it appears that the mechanisms may be somewhat selective for cone type.

\section{SPECTRAL PROCESSING IN AMACRINE CELLS}

\section{AC Characteristics}

As a group, and across all vertebrates, ACs are the most diverse class of retinal neuron. ACs are categorized by their physiological response to light, their great variety of neurotransmitter expression as determined using immunolabeling, their dendritic morphology, and dendritic lamination patterns in the IPL. The different types of ACs range from 43 in roach (Wagner and Wagner, 1988) to 22 in cat (Kolb et al., 1981) to $\sim 30$ in rabbit (MacNeil et al., 1999; Masland, 2012). Physiological responses of ACs are similarly diverse. Light stimulation evokes sustained or transient, ON, OFF, or ON-OFF responses in both mammalian (Nelson, 1982; Nelson and Kolb, 1985; Stafford and Dacey, 1997; Menger and Wässle, 2000) and non-mammalian (Kaneko, 1970, 1973; Pang et al., 2002; Miller et al., 2006; Zhang and Wu, 2010) retinas.

Structural and functional diversity is also present in zebrafish ACs where $\sim 28$ morphological types have been identified in $5 \mathrm{dpf}$ larval retina (Jusuf and Harris, 2009). Many larval AC types are also present in adults, as determined by dye (Connaughton et al., 2004) and/or immunolabeling (Marc and Cameron, 2001; Yazulla and Studholme, 2001; Arenzana et al., 2006; Yeo et al., 2009; Jang et al., 2011). These cells exhibit narrow, medium, or wide field dendritic arbors (Jusuf and Harris, 2009; Lewis et al., 2015) and are widely distributed over the entire retina (Yeo et al., 2009; Torvund et al., 2017); although it appears the density of parvalbumin s4, and tyrosine hydroxylase (dopaminergic) types is greater in temporal-ventral, or ventral retina than nasal retina (Yeo et al., 2009; Jang et al., 2011). In adult zebrafish, AC light responses are either transient or sustained, with excitation observed at light $\mathrm{ON}$, light OFF, or both light $\mathrm{ON}$ and light OFF (Torvund et al., 2017). Most dendritic branching patterns are highly planar and narrowly restricted to single strata within the IPL. Both monostratified 
A

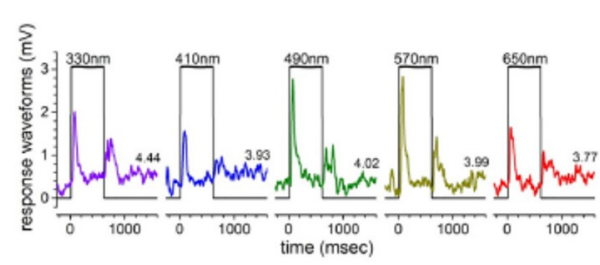

B

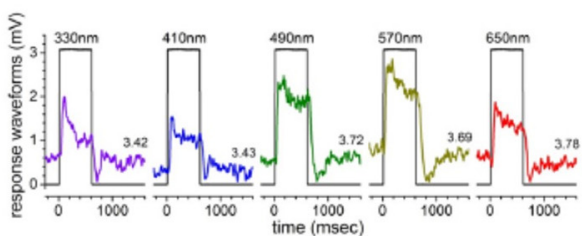

C

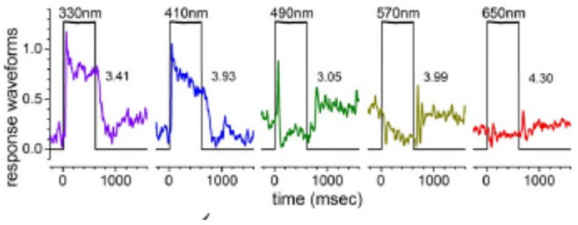

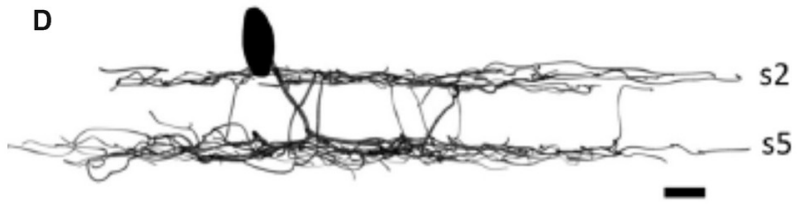

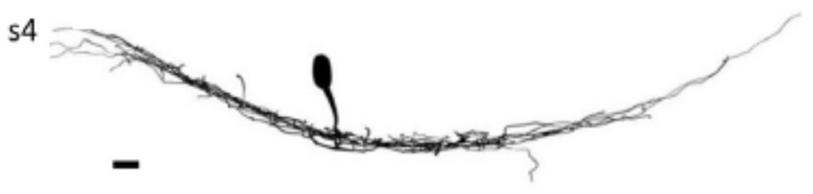

$\mathbf{F}$

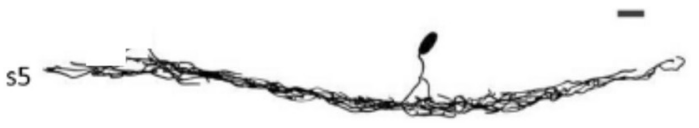

FIGURE 6 | Spectral responses of ACs are associated with specific cell types. Transient ON-OFF amacrine cells (AC) responses (A) were characteristic of bi-stratified ACs with dendrites in both the OFF- and ON-sublaminae (B). In contrast, sustained ON responses (C) were observed in ACs with a dendritic arbor monostratified in sublamina $b$ (D). Spectrally multiphasic C-type responses were primarily observed in ON-cells, as shown in the biphasic response (E) from a monostratified AC with dendrites in s5 of sublamina $b$ (F) (Torvund et al., 2017).

types (one branching plane) and bistratified types (two branching planes) are observed (Connaughton et al., 2004). Diffuse dendritic branching through multiple IPL strata was uncommon.

\section{ON-OFF Amacrine Cells Select Red Cone Signals}

ON-OFF responses in zebrafish are characteristic of all bistratified ACs (Figures 6A,B). Most of these have processes in both IPL sublamina $a$ and $b$, though some ON-OFF cells have processes bistratified only within sublamina $a$ (Torvund et al., 2017). These cells respond to spectral stimuli ranging from $330 \mathrm{~nm}$ to $650 \mathrm{~nm}$; however, modeling of their responses indicates virtually exclusive input from red cones (Torvund et al., 2017), both at light ON and light OFF. For calcium imaging, ACs can be marked by the inhibitory-interneuron selective transgene ptfla:gal4 (Jusuf and Harris, 2009). Marked cells express the synaptic calcium reporter transgene UAS:SyGCAMP3 (Rosa et al., 2016). In the IPL, bands of ON-OFF responding processes and synapses can be found in both sublamina $a$ and sublamina $b$, a result consistent with the existence of ON-OFF bistratified AC types. This method, however, is not able to directly link both bands to actions from single bistratified ACs. The frequency responses of these ON-OFF signals included different populations peaking at either $\sim 5 \mathrm{~Hz}$ or $\sim 10 \mathrm{~Hz}$.

\section{ON-Sustained and OFF Amacrines Sum Red and Green Cone Signals}

Zebrafish OFF-type ACs, like ON-OFF types, receive dominant input from red cones, with lesser input from green or blue cones (Torvund et al., 2017). These cells are monostratified in either s1 or s2 of sublamina $a$. ON-type AC, with monostratified dendrites in $s 4$, or rarely $s 3$, receive mixed luminosity signals from red and green cones, leading to mid-spectral sensitivity peaks (Figures 6C,D). The ON ACs were sustained types, not excited at light OFF, and contributions from blue and UV cones are noticeably lacking in these non-opponent responses (Torvund et al., 2017). The dendrites of both ON and OFF ptf1a ACs, marked for synaptic calcium responses, labeled distinct IPL strata, with a major ON band in sublamina $b$, and a major OFF band in sublamina $a$. In addition, calcium imaging suggests a lower intensity representation of both these response types throughout retinal depth (Rosa et al., 2016). Crossover GABAergic inhibition from ON-ACs appears to shape the frequency response characteristics of OFF-BC terminals (Rosa 
et al., 2016), leading to the speculation that sustained ON-ACs contribute "low pass" characteristics to OFF-BC boutons.

\section{C-Type Amacrine Cells Subtract Cone Signals}

Unique as compared to mammals, some zebrafish ACs are coloropponent. UV cone inputs contribute significantly to coloropponent (C-type) responses in zebrafish AC. The dendrites of all these C-type ACs ramify deep in sublamina $b$, indicating they are ON-type cells morphologically, though physiologically the response sign depends on wavelength (Figures 6E,F). In adult retina, both spectrally biphasic and triphasic AC responses are present, as also observed in $\mathrm{HC}$ spectral responses (Connaughton and Nelson, 2010). Biphasic AC responses include blue-yellow and red-green units. Red-green opponent cells depolarized to red, but hyperpolarized to green, blue and UV stimulation; while blue-yellow opponent cells responded with a sustained depolarization to short wavelength stimulation, but hyperpolarized to long wavelengths (Torvund et al., 2017). Some triphasic ACs depolarized to UV, hyperpolarized to blue, and depolarized to green. Interestingly, inclusion of (marginally significant) red cone inputs to the triphasic response would cause it to be reclassified as a tetrachromatic AC response (Torvund et al., 2017). Calcium imaging studies have found color-opponent $\mathrm{BC}$ terminals within the layer of dendritic branching of coloropponent ACs (Zimmermann et al., 2018). The bistratified, color-opponent Cab bipolar of Giant Danio also sends a terminal bouton to this same layer (Wong et al., 2005). Taken together these studies identify a potential synaptic input for C-type ACs. Wide dendritic fields, sometimes seen with dye coupling, suggest a wavelength-dependent modulatory role.

\section{MORPHOLOGY AND PHYSIOLOGY OF RETINAL GANGLION CELLS}

\section{GC Physiology in Vertebrates}

As the output neuron of the retina, there have been many studies documenting light responses of retinal GCs. In fact, coloropponent GCs have been documented in a variety of species, including, but not limited to, monkey (De Monasterio and Gouras, 1975; Zrenner et al., 1983; Dacey and Lee, 1994; Calkins et al., 1998; Sun et al., 2006; Crook et al., 2009; Lee and Sun, 2009; Dacey et al., 2014; Silveira et al., 2014), cat (Daw and Pearlman, 1970; Crocker et al., 1980; Guenther and Zrenner, 1993), wallaby (Hemmi et al., 2002), rabbit (Caldwell and Daw, 1978; De Monasterio, 1978; Mills et al., 2014), guinea pig (Yin et al., 2009), mouse (Chang et al., 2013), turtle (Bowling, 1980; Rocha et al., 2008), chick (Zhou et al., 2005), and fish (Wagner et al., 1960; Witkovsky, 1965; Daw, 1968; Raynauld, 1972; Spekreijse et al., 1972; Van Dijk and Spekreijse, 1984; Mackintosh et al., 1987; Bilotta and Abramov, 1989; Sakai et al., 1997). Therefore, the presence of spectrally selective GC responses in zebrafish would not be surprising. A wide range of GC characteristics/response types makes sense as these cells receive, integrate and process information from $\mathrm{BC}$ and $\mathrm{AC}$ about various parameters of the visual scene.

\section{Zebrafish GC Morphology, Development and Tectal Projection}

Mammals, in general, have a greater number of morphological types of GCs (Kolb et al., 1981; Sanes and Masland, 2015) than zebrafish (Mangrum et al., 2002). The 11 types identified in adult zebrafish (Figure 7) are grouped as either wide-field (2), narrow-field (4), multistratified (3), or diffuse (2) based on dendritic extent and patterns of stratification (Mangrum et al., 2002). A main reason for less types in zebrafish is a closer grouping of cell body diameters $(5-8 \mu \mathrm{m})$ and dendritic field diameters $(80-200 \mu \mathrm{m})$ as compared to mammals (cat: 10-40 $\mu \mathrm{m}$ cell bodies; $20-900 \mu \mathrm{m}$ dendritic fields; (Kolb et al., 1981). A wide spread of metrics allows for more type-features to be distinguished. In mouse retina, similar to zebrafish, GC dendritic fields are restricted in range (150-450 $\mu \mathrm{m}$; Sun et al., 2002). The greatest density of zebrafish GCs occurs in a temporalventral patch similar to the "SZ", a visual space used for feeding (Mangrum et al., 2002; Zimmermann et al., 2018).

Time-lapse imaging experiments in larval zebrafish (Mumm et al., 2006) discovered diverse dendritic growth patterns and laminar targeting mechanisms used by GCs in the IPL, resulting in 15 stratification patterns. GC input to the tectum is somewhat segregated, with inputs relaying similar information (such as stimulus direction) going to similar tectal areas (Johnston and Lagnado, 2012). Though these inputs to the tectum are functional by $66 \mathrm{hpf}$, it is not until $78 \mathrm{hpf}$ that tectal neurons begin to display mature responses. This suggests that GCs are capable of information processing before structural development in the retina is complete (Niell and Smith, 2005).

\section{Ganglion Cell Light Responses}

Light responses of larval zebrafish GCs are either transient or sustained, with ON-, OFF- and ON-OFF subtypes (Emran et al., 2007). Most ON-OFF cells are bistratified in sublaminae $a$ and $b$, while ON- and OFF-cells are monostratified (Zhang et al., 2010). Between $2 \mathrm{dpf}$ and $4 \mathrm{dpf}$ zebrafish GCs undergo depolarizing to hyperpolarizing shift in GABAergic inhibitory $\mathrm{E}_{C l}$ (Zhang et al., 2010), a process common to vertebrate early neuronal development (Li et al., 1998). Stable light responses are recorded as early as $4 \mathrm{dpf}$ (Zhang et al., 2010) and color-opponent and non-opponent responses are evident at $5 \mathrm{dpf}$ and $6 \mathrm{dpf}$, when responses are dominated by spectrally multiphasic types (Connaughton and Nelson, 2015). The most common spectral type is the triphasic GC response with bursts of spikes to both long and short wavelength stimuli, but inhibited firing at middle wavelengths. Other multiphasic responses include biphasic, tetraphasic and pentaphasic units (Connaughton and Nelson, 2015). Like adult ACs, red cone inputs are prominent in larval GC spectral responses. However, most GC responses include significant and commonly dominant, UV excitation, resulting in multiphasic spectral properties. Very few larval zebrafish GCs are spectrally monophasic (Figure 8). In adult zebrafish, light-evoked spike discharges are seen in the optic nerve, particularly ON-OFF types ( $\mathrm{Li}$ and Dowling, 2000; Huang et al., 2005), but the spectral properties are not known. 


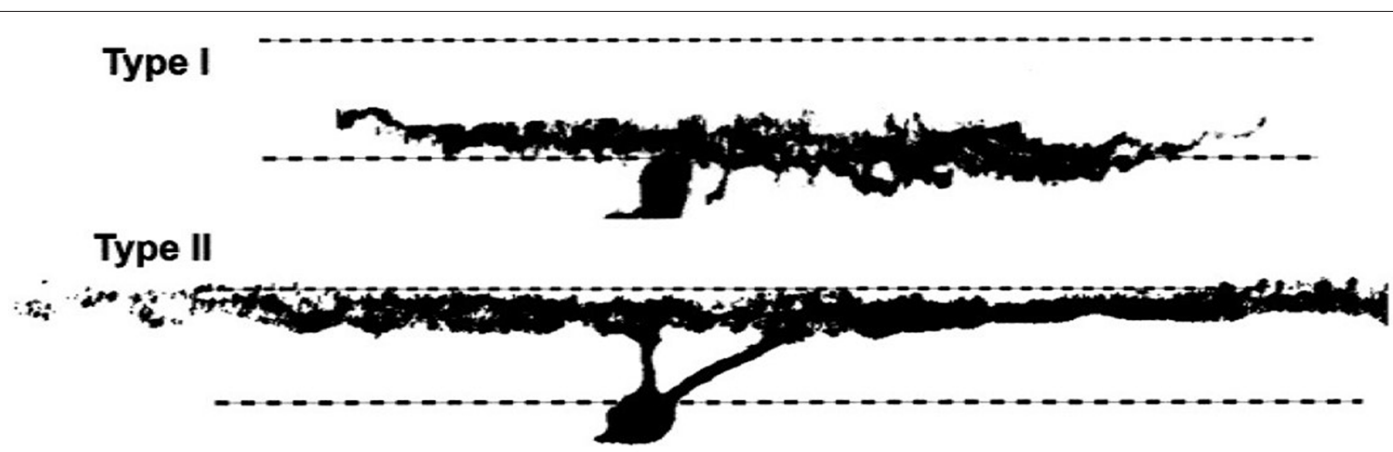

Type III

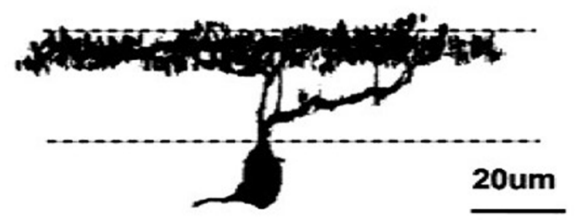

Type V

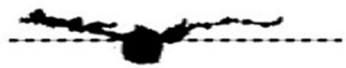

Type VII

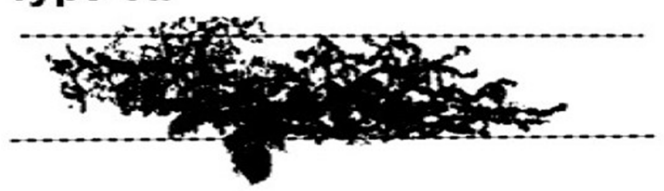

Type IV

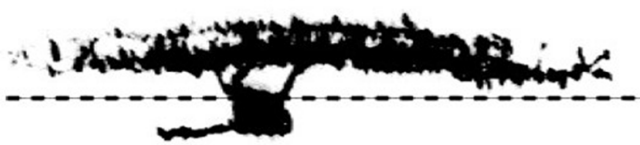

\section{Type VI}

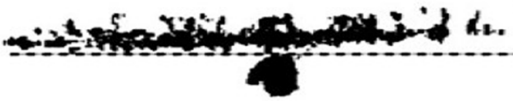

\section{Type VIII}

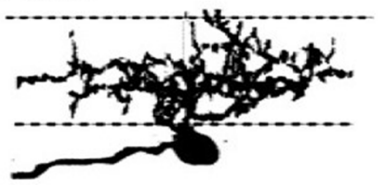

Type IX

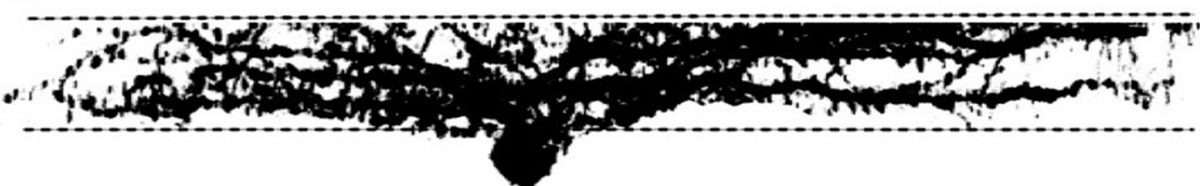

\section{Type X}

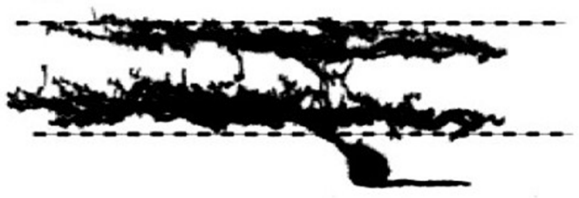

Type XI

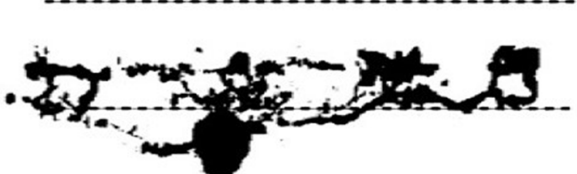

FIGURE 7 | Zebrafish ganglion cells (GCs). Di-I labeling of GCs in whole mount tissue identified 11 morphological types, based on dendritic arborization patterns in the IPL. These patterns included processes restricted to 1-2 sublaminae, as well as more diffuse arborization patterns. Reproduced with permission from Mangrum et al. (2002).

\section{WAVELENGTH PROCESSING CIRCUITRY IN ZEBRAFISH}

The different subtypes of second- and third-order neurons in zebrafish receive inputs from single or, more often, multiple cone PRs, resulting in spectrally monophasic and multiphasic responses. As a result, the signals from each cone type are relayed, through both feedforward and feedback circuitry, throughout the entire retina. One feature of this intermixing of cone signals is both synergistic and antagonistic interactions between different cone signals in distal neurons, such as $\mathrm{HC}$ and $\mathrm{BC}$, a feature also noted in $\mathrm{AC}$ and $\mathrm{GC}$ of the inner retina. The spectral properties of GCs, retinal output neurons, are similar to the color-opponent spectral responses of HCs, suggesting one of the 


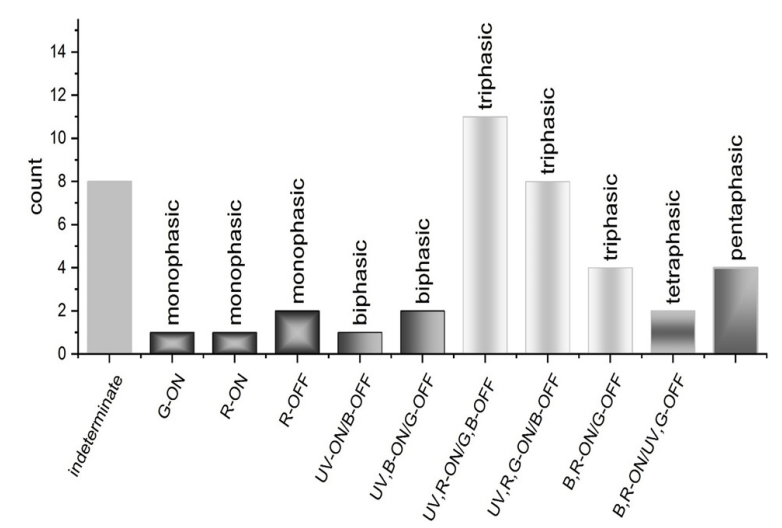

FIGURE 8 | GC spectral responses. Loose patch recordings from larval zebrafish GCs revealed a diversity of response types, most of which are spectrally multiphasic. Triphasic responses were the most abundant type identified and could be subdivided into three distinct spectral patterns. Bi-, tetra-, and pentaphasic responses were also recorded (Connaughton and Nelson, 2015).

origins of GC spectral processing lies in distal retina, with the cone connectivity patterns of $\mathrm{HC}$ and $\mathrm{BC}$. One expects there is further selective integration of $\mathrm{BC}$ and $\mathrm{AC}$ physiological types onto the dendrites of GC receptive fields in the IPL, resulting in even greater diversification and refinement of spectral properties. The dominance of red cone signals in spectrally monophasic AC types is reminiscent of the L-type signals from $\mathrm{H} 1 \mathrm{HCs}$, suggesting the existence of an L-type BC pathway. Despite the evidence for a mixing of cone signals in the image-processing circuits of the inner retina, existing evidence suggests that signals from the 4 retinal cone types in zebrafish are not treated equally.

\section{Red Cone Signals}

Red cones are only $1 / 3$ of adult cone types. Nonetheless, red cone signals dominate spectral responses in $\mathrm{HC}$ and AC. These red (LWS) signals are relayed directly from the principal member of the double cone to $\mathrm{H} 1 \mathrm{HCs}(\mathrm{Li}$ et al., 2009) resulting in red-dominated monophasic (L1- or L2-type) physiologies in 2/3 of HCs studied (Connaughton and Nelson, 2010). Even though contacting them, $\mathrm{H} 1 \mathrm{HCs}$ do not receive physiological signals from blue (SWS2) cones, and do not contact UV (SWS1) cones at all. LWS cones are included in seven of nine of BC connectivity patterns or $87 \%$ of 321 BCs studied (Li et al., 2012), potentially accounting for the prevalence of red cone signals seen in ACs (Torvund et al., 2017). However, these BC pathways, while contacting red cones, are not red cone selective, as green (MWS) cones overlap, comingling in all but one of these same BC connectivity patterns and 93\% of BCs studied (Li et al., 2012).

Non-color-opponent AC responses are either selective for or dominated by red cone signals; these cells are OFF-stratified, ON-stratified, and ON-OFF bistratified cells, altogether accounting for $89 \%$ of recorded cells (Torvund et al., 2017). The variety of AC stratification patterns in this group suggest that $\mathrm{AC}$ processes receiving LWS-selective cone inputs are present throughout the depth of the IPL
(Torvund et al., 2017), consistent with direct input from red cone contacting, and physiologically red cone dominated BCs, also presumably of multiple stratification types. In contrast to adult ACs, LWS inputs to GCs in larval zebrafish retinas contribute mainly to spectrally multiphasic responses. For the latter, red cone inputs are always excitatory (Connaughton and Nelson, 2015), but the responses are dominated by excitation from UV cones. The contrast between dominant AC and GC red cone spectral patterns presents a dilemma, and it is unclear at present how large a role larval development plays, as b-wave spectral sensitivity progresses from UV-dominated in larvae to a more broadly sensitive pattern in juveniles and adults (Saszik et al., 1999). A reasonable conjecture is that both non-opponent and opponent BC pathways exist for red cone signals. This idea is consistent with the finding of a population of red cone opponent ACs in adults with a unique stratification pattern (Torvund et al., 2017).

\section{Green Cone Signals}

Despite a numerical representation in adults identical to red cones, green cone signals are not dominant in zebrafish physiology. In the outer retina, while red cones dominate $\mathrm{H} 1 \mathrm{HC}$ responses, UV cones dominate one physiological subtype of $\mathrm{H} 3$, and blue cones dominate the other, there is no HC strictly devoted to excitation from green cones. These signals appear as complementary components in $\mathrm{H} 1 \mathrm{HC}$, particularly the L2-type response and $\mathrm{H} 2 \mathrm{HC}$ biphasic signals, where they combine with blue cone signals. The most selective and prominent role of green cone signals in the outer retina are as the inhibitory (depolarizing) elements in triphasic and tetraphasic $\mathrm{HC}$ responses (Connaughton and Nelson, 2010).

In ACs, green cone inputs to non-color-opponent cells were small and found mainly in sustained-ON AC, with processes monostratified either in the OFF sublamina or in the distal-most layer of the ON sublamina (Torvund et al., 2017). Green cone signals were seldom identified in the numerically dominant ON-OFF types. No ACs that selectively represent green cone signals have been encountered (Torvund et al., 2017). The relative absence of MWS signals in ACs is mysterious, unless green cone-to-BC synapses are commonly either inactive, inhibitory, or opponent. In calcium imaging physiology of BC boutons (Zimmermann et al., 2018) it does appear that the most common form of BC color opponency is red excitatory, green inhibitory (Figure 5). These red-ON, green-OFF boutons localize mainly in s2, s3 of IPL sublamina $a$. Green cones are the only type that selectively innervate $\mathrm{BCs}$, in fact there are three varieties of OFF stratifying BCs that only contact green cones (Li et al., 2012). The green cone signals appear to be largely inhibitory (Connaughton and Nelson, 2015), and speculatively, the inhibition might involve OFF-type, or color-opponent OFFtype, green cone BCs. However, in adults, the spectrally triphasic, green cone inhibited, color-opponent AC did not co-stratify with green cone $\mathrm{BC}$ terminals in sublamina $a$.

\section{Blue and UV Cone Signals}

In outer retina, blue and UV cone signals are represented in about $1 / 3$ of recorded HC. Blue (SWS2) cones contact H1, 
H2 and H3 HC (Li et al., 2009), but only contribute signals to biphasic $(\mathrm{H} 2)$ and blue-preferring triphasic $(\mathrm{H} 3)$ responses (Connaughton and Nelson, 2010). UV cones directly connect only to H3 cells ( $\mathrm{Li}$ et al., 2009). However, UV inputs to $\mathrm{H} 3$ cells appear variable, as this morphological type can generate three different spectral responses (Connaughton and Nelson, 2010): (1) UV-excited spectrally triphasic responses dominated by UV cone excitation; (2) tetraphasic (UV-inhibitory); and (3) blue-preferring triphasic responses excited by both UV and blue cones. Spectrally multiphasic patterns are presumed evidence of feedback to blue and UV cones from HC types receiving stimulation from LWS cones (Li et al., 2009; Connaughton and Nelson, 2010) to generate HC multiphasic responses.

In adult inner retina, stimulation of blue and UV cones contributes to biphasic and triphasic responses in zebrafish ACs, a pattern similar to outer retina. These include a UV-depolarizing blue-yellow opponent biphasic unit and UV-depolarizing triphasic responses (Torvund et al., 2017). Short wavelength inputs to larval GCs elicit spectrally triphasic responses, similar to triphasic HC responses (Connaughton and Nelson, 2015). Interestingly, adult ACs with C-type responses have processes exclusively in sublamina $b$, suggesting a functional segregation of short wavelength BC-to-AC synapses in the IPL. Adult connectomic analysis identified $3 \mathrm{BC}$ types directly postsynaptic to UV cones with axon terminals in sublamina $b$, and $5 \mathrm{BC}$ types postsynaptic to blue cones (Li et al., 2012), suggesting there are a relatively few, possibly selective, circuits that relay short wavelength signals to inner retina, and that short wavelength cone signals are commonly conveyed in a color-opponent pathway.

\section{Stratification of IPL Cone Signals}

There may be some segregation of cone signals in the zebrafish IPL. BC connectomics provides pathways for red, green, blue and UV cone signals into all IPL strata. This homogeneity is partly enforced by BCs with multistratified axon terminals, as well as the prevalence of BCs contacting multiple cone types (Li et al., 2012). The finding of dominant red cone signals in all non-opponent ACs, regardless of stratification pattern, is in accord with a distribution of L-type, or achromatic, red cone signals throughout the IPL (Torvund et al., 2017). Nonetheless, there are some imbalances. The RRod type BC conducts red cone (and rod) signals only, and projects to IPL sublamina $b$. The solely green cone contacting BCs project only to s1 and s3 of sublamina $a$, with most boutons in s3 (Li et al., 2012). Depolarizing sustained ACs stratify in s3-s4. In addition to red cone signals, these cells are strongly excited by green cone stimulation (Torvund et al., 2017). Over $60 \%$ of BC types project to sublamina $a$ (Li et al., 2012), a curious imbalance. In calcium imaging studies of BC boutons, Zimmermann et al. (2018) found that the IPL strata containing achromatic OFF-BC boutons may be much narrower than previously supposed, localized to s1 and not all strata of sublamina $a$. The remaining s2-s3 band contains coloropponent $\mathrm{BC}$ boutons of various types. There is also an s5 coloropponent band, perhaps innervating the color-opponent ACs that branch in s5 (Torvund et al., 2017). Torvund et al. (2017) proposed that the multistratified GBUV BC types ( $\mathrm{Li}$ et al., 2012) might be the color-opponent pathway innervating coloropponent ACs, a theory yet to be tested but consistent with the color-opponent $\mathrm{BC}$ axon terminal distribution (Wong and Dowling, 2005; Zimmermann et al., 2018). Stratum s4 and thereabouts is the true achromatic ON-type band. Zimmermann et al. (2018) find that IPL banding varies with retinal region as well, with UV excited boutons being broadly prevalent in the "SZ". The indications are that there are multiple functional layers in zebrafish IPL, both for chromatic and achromatic processing.

\section{COMPARISON WITH MAMMALIAN COLOR CIRCUITRY}

In mammals, there are well-defined, specific inner and outer retinal circuits for rod and cone signals. Rod signals are relayed through rod $\mathrm{BCs}$ (RBCs) to $\mathrm{AII} \mathrm{ACs}$ and then to ON-GCs through gap junctions with ON-BC terminals (Kolb and Famiglietti, 1974). Cone signals are relayed through cone BCs to GCs (Kolb, 1970). As true for most fish, zebrafish have mixed input (mb) BCs, a close analog of mammalian RBCs, but receiving inputs from both rods and cones. In mammals, cones synapse on HC dendrites, and rods synapse on HC axon terminals (Nelson et al., 1975; Kolb, 1977; Dacheux and Raviola, 1982). In zebrafish, rods synapse on a separate HC type, while cones selectively innervate 3 distinct $\mathrm{HC}$ types and 4 different BC types (Li et al., 2012). Overall, it appears that rod and cone signals in zebrafish, like mammals, are selectively sampled by retinal interneurons. Zebrafish HCs are either spectrally monophasic (red cone signals) or multiphasic (color opponency among cone signals, (Connaughton and Nelson, 2010); while only spectrally monophasic patterns appear in mammalian HCs. Mammalian HC axon terminals are physiologically rod selective, while the mammalian $\mathrm{HC}$ cell bodies mix red cone, rod and UV/blue cone signals (Steinberg, 1969; Dacheux and Raviola, 1982; Nelson, 1985; Dacey et al., 1996).

There are BCs selective for UV cones in mammals (Mariani, 1984; Haverkamp et al., 2005). In contrast, there is no anatomically UV cone selective BC in zebrafish ( $\mathrm{Li}$ et al., 2012). Nonetheless, UV-selective BC physiology is likely present (Saszik et al., 2002; Zimmermann et al., 2018). Zebrafish GC responses include short-wavelength color-opponent responses, as reported in other species. In primate retina, for example, the blue-ON/yellow-OFF response of small bistratified GCs has been particularly well described (Dacey, 1999; Marshak and Mills, 2014). This spectrally multiphasic response is due to feedback circuitry involving $\mathrm{HCs}$ in outer retina. In inner retina, it is attributed to separate inputs from $\mathrm{ON}$ - and OFF$\mathrm{BCs}$, which themselves are postsynaptic to different cone types, as well as chromatic AC inputs (Marshak and Mills, 2014). It is likely that the multiphasic responses dominated by UV signals observed in larval zebrafish GCs similarly integrate and reflect inputs from UV-selective outer retinal circuitry involving $\mathrm{HCs}$ and direct inputs from spectrally selective presynaptic BCs and/or ACs. 


\section{COLOR PREFERENCE, PERCEPTION AND BEHAVIOR}

Zebrafish display color discrimination or preference when given a choice between different sections of a tank that have different background colors (Colwill et al., 2005; Risner et al., 2006; Avdesh et al., 2012; Ahmad and Richardson, 2013; Oliveira et al., 2015; Park et al., 2016). Most studies report a natural preference for blue/short wavelength light in both adult (Colwill et al., 2005; Risner et al., 2006; Bault et al., 2015; Oliveira et al., 2015; Peeters et al., 2016) and larval (Park et al., 2016; Peeters et al., 2016) fish. A few studies, in contrast, report a natural preference for red/long wavelength light (Avdesh et al., 2012; Ahmad and Richardson, 2013), which may be associated with food/foraging and be related to color of prey items (Spence and Smith, 2008).

In behavioral testing, color preference is best explained by a multiple-mechanisms model that includes both non-opponent (UV, B) and opponent (G-B and G-R) systems (Risner et al., 2006). This model is also most accurate in describing spectral sensitivities of ERG b-wave and ON-tectal responses in zebrafish (McDowell et al., 2004), suggesting behavioral responses reflect physiological processing of the visual scene. Interestingly, though color choice experiments indicate zebrafish can behaviorally distinguish color stimuli, the optomotor response (OMR), a standard vision-based behavior used to identify mutant strains, is "color blind" (Krauss and Neumeyer, 2003; Orger and Baier, 2005) as it is dominated by LWS (red) cones in adults (Krauss and Neumeyer, 2003) and pooled inputs from red and green cones in larvae (Orger and Baier, 2005). OMRs can be reduced, though, when UV or B cones are selectively ablated (Hagerman et al., 2016), suggesting short wavelength cones do contribute to the OMR, possibly in an inhibitory manner (Krauss and Neumeyer, 2003; Hagerman et al., 2016).

\section{ZEBRAFISH AS MODELS OF RETINAL DISEASE}

There have been several recent reviews detailing the applicability of zebrafish to the study of ocular/retinal diseases (Gross and Perkins, 2008; Bibliowicz et al., 2011; Link and Collery, 2015). These reviews highlight the experimental strengths of zebrafish: similar retinal/eye anatomy with humans, rapid development and large clutch size, easy manipulation and phenotype observation, and amenability of genome editing techniques to generate mutant and transgenic lines (Bibliowicz et al., 2011; Link and Collery, 2015). Of the $>20$ diseases for which zebrafish are used, $\sim 50 \%$ target PRs/PR layer (Link and Collery, 2015), and 13 specific genes associated with PR degeneration have been identified (Brockerhoff and Fadool, 2011). Behavioral studies using the optokinetic response (OKR; Brockerhoff et al., 1995), the escape response (Li and Dowling, 1997), or the visual motor response (Emran et al., 2008), coupled to ERG recordings allowed functional assessment of mutant phenotypes. Interestingly, many of the mutations leading to PR degeneration are not associated with transduction, but with protein trafficking (Brockerhoff and Fadool, 2011), consistent with the high metabolic demand and almost-constant functioning of retinal PRs. Here, we focus on those zebrafish lines with mutations in cone PRs. These studies have largely been performed with larval (5-7 dpf) zebrafish because, at this age, the cone-rich retina contains few/no rods (Holzhausen et al., 2009).

\section{Mutations Affecting All Cone Types}

The OKR is a visually-guided behavior based on saccadic eye movements as a stationary animal tracks a moving grating. This is a reliable test that can be elicited as early as $\sim 4 \mathrm{dpf}$ in zebrafish (Brockerhoff et al., 1995; Neuhauss, 2003). Brockerhoff et al. $(1995,1997,1998)$ were the first to apply this technique to the identification of mutant phenotypes. Most of these behaviorallyidentified zebrafish were later found to have mutations in cone-specific genes.

One of the first mutants identified was no optokinetic response a (noa). As the name suggests, noa larvae do not display an OKR. These mutants have ERG recordings with normal a-waves, but abnormal b-waves (Brockerhoff et al., 1995), consistent with altered glutamate responses in postsynaptic BCs (Connaughton, 2001). Subsequent, molecular analysis identified two alleles of noa: $m 631$ and a13 (Taylor et al., 2004). noa $a^{a 13}$ mutants (originally no optokinetic response b, (Taylor et al., 2004) have a deficient dihydrolipoamide-S-acetyltransferase (dlat) gene, resulting in the absence of the $\mathrm{E} 2$ subunit of the enzyme pyruvate dehydrogenase (PDH; Taylor et al., 2004). PDH is a critical enzyme involved in ATP production in mitochondria because it catalyzes the reaction that converts pyruvate to Acetyl Co A (Karp, 1999). Absence of this enzyme results in PDH deficiency, an inherited metabolic disorder (Barnerias et al., 2010; Patel et al., 2012). The dlat (noa $\left.{ }^{a 13}\right)$ mutant is, therefore, a model for human PDH deficiency.

no optokinetic response $c(\mathrm{nrc})$ mutants, in addition to an absent OKR, have a diverse phenotype that includes floating ribbons in cone pedicles (Allwardt et al., 2001) and reduced numbers of unevenly distributed synaptic vesicles (Van Epps et al., 2004). Abnormal ERG recordings (Allwardt et al., 2001) revealed a light adaptation defect in distal retina (Van Epps et al., 2001). ON-GC responses in inner retina are also reduced/absent (Emran et al., 2007). Molecular analysis identified the $n r c$ mutation as a premature stop codon in the synaptojanin 1 (SynJ1) gene (Van Epps et al., 2004) in cone PRs (Holzhausen et al., 2009). Synaptojanin-1 is strongly expressed in brain $^{1}$ and the synaptojanin-1 protein is involved in endocytosis of clathrincoated vesicles (Perera et al., 2006) in nerve terminals.

A cone-specific mutation is also observed in zebrafish no optokinetic response $f$ (nof) mutants. nof fish have a nonsense mutation in the gene coding for the $\alpha$-subunit of cone transducin (TaC; Brockerhoff et al., 2003). Development of the transgenic line $T G(3.2 \mathrm{~T} \alpha C P$-EGFP) allowed visualization of $\mathrm{T} \alpha \mathrm{C}$ in all zebrafish cone types, making nof mutants a model for achromatopsia (Kennedy et al., 2007). Interestingly, though nof cones lack transducin, they do respond to bright light stimuli, albeit at a much-reduced level (Brockerhoff et al., 2003).

\footnotetext{
$\overline{{ }^{1} \text { https://www.ncbi.nlm.nih.gov/gene/8867 }}$
} 
A mutation in the cone cGMP-phosphodiesterase $\alpha$ subunit ( $p d e 6 \alpha^{1}$ or $p d e 6 c$ ), also causes cone degeneration (Stearns et al., 2007; Nishiwaki et al., 2008) in zebrafish. cGMP-PDE is an enzyme complex located in $\mathrm{PR}$ outer segments that is part of the phototransduction cascade (Rodieck, 1998). In mouse rods, absence/mutations in either the $\alpha$ (Huang et al., 1995), $\beta$ (Pittler and Baehr, 1991), or $\gamma$ (Tsang et al., 1996) subunits of cGMP-PDE result in rod degeneration. cGMP-PDE in zebrafish cones is similarly required as mutations lead to cone-specific degeneration.

\section{Mutations/Treatments Affecting Specific Cone Types}

The generation of knockout (KO) and mutant lines has also identified genes specific to a given cone type. The transcription factor $T b x 2 b$, for example, is necessary for UV cone formation (Alvarez-Delfin et al., 2009) as a mutation in $t b \times 2 b$ results in the conversion of UV cones to rods, resulting in the lots-of-rods (lor) phenotype (Alvarez-Delfin et al., 2009). Though lor zebrafish have a strong OKR, UV opsin expression in larval retinas is deficient. All other cone types are present and $t b \times 2 b$ mutants have an even and abundant distribution of rods over the entire retina. Similarly, the transcription factor sine oculis homeobox homolog 7 ( $\operatorname{six} 7$ ) is required for green cone development (Ogawa et al., 2015). PRs in six7 KO larvae don't express any of the four, green opsin ( $\mathrm{RH} 2-1$ to $\mathrm{RH} 2-4)$ genes, resulting in a loss of green cones that persists to adulthood. Interestingly, the six7 KO phenotype also includes reduced blue opsin expression (larval stage), increased number of rods (larvae), and a switch in red opsin expression (adults; Ogawa et al., 2015). Finally, red cone fate is determined by thyroid hormone receptor $\beta 2(\operatorname{tr} \beta 2)$ expression (Suzuki et al., 2013) as knockdown of $\operatorname{tr} \beta 2$ results in a loss of red cones, but an increase in UV cones (Suzuki et al., 2013). Red cone loss is also selective in partial optokinetic response b (pob) mutants (Brockerhoff et al., 1997). pob zebrafish are red color blind due to rapid degeneration of red cones. PR loss in pob is due to a mutation in the pob gene, which codes for a protein required for red cone survival (Taylor et al., 2005).

Allison and colleagues have developed transgenic zebrafish lines in which a single class of PR can be chemically ablated (Fraser et al., 2013; Hagerman et al., 2016). These lines are key in determining how removal of one cone type may alter the existing PR mosaic as well as how the retina will respond. The zebrafish retina continues to grow throughout the life of the fish and is able to regenerate cells in response to damage (reviewed in Brockerhoff and Fadool, 2011). Chemical ablation of a single cone type in adult retina can trigger retinal regeneration (Fraser et al., 2013; Hagerman et al., 2016). For example, selective ablation of UV cones stimulates the formation of new UV cones, at a higher density than predicted (Fraser et al., 2013). This recovery and regeneration is rapid: behavioral responses (OMR) are restored in $72 \mathrm{~h}$

\section{REFERENCES}

Ahmad, F., and Richardson, M. K. (2013). Exploratory behavior in the open field test adapted for larval zebrafish: impact of environmental complexity. Behav. Processes 92, 88-98. doi: 10.1016/j.beproc.2012.10.014
(Hagerman et al., 2016). Selective loss of blue cones, however, results in an even faster regenerative response, with behavioral responses restored in $24 \mathrm{~h}$ (Hagerman et al., 2016). The rapid regeneration capabilities of zebrafish retinal tissue, and the ability of this tissue to respond to the selective loss of a given cone type, is an important step in determining mechanisms that could be used to restore cell loss after retinal degeneration.

Finally, other studies have induced diseases with retinal complications using non-molecular mechanisms. For example, prolonged hyperglycemia, characteristic of diabetes, can be induced by either immersing zebrafish in a glucose solution (Gleeson et al., 2007; Alvarez et al., 2010) or through streptozotocin injection (Olsen et al., 2010; Intine et al., 2013), both of which result in changes to the retina, making zebrafish a model for diabetic retinopathy. In addition to retinal thinning (Gleeson et al., 2007; Olsen et al., 2010) and changes to retinal vasculature (Alvarez et al., 2010), there are also marked changes to cone PRs in hyperglycemic zebrafish retinas with double cones displaying the most severe alterations (Alvarez et al., 2010).

\section{CONCLUSION}

Zebrafish are capable of rich color processing due to the presence of four cone types that allow detection of light ranging from UV to red. After stimulation of the phototransduction cascade in cones, spectral signals are immediately processed and modified in outer retina through synapses with HC. BC signaling relays spectral information to inner retina, where multiple feedforward inputs converge on AC and GC and feedback inputs from AC further modify spectral signals. These ON-signals are faithfully relayed to the tectum. As a result, zebrafish are able to behaviorally discriminate color and display innate color preferences. This elaborate signaling, coupled to well-known retinal anatomy and targeted genetic manipulation, has resulted in zebrafish that exhibit mutation-induced red blindness (Brockerhoff et al., 1997), UV blindness (AlvarezDelfin et al., 2009), and green blindness (Ogawa et al., 2015). Zebrafish also serve as models for vision disorders, such as diabetic retinopathy (Gleeson et al., 2007; Alvarez et al., 2010), retinitis pigmentosa (Baye et al., 2011), achromatopsia (Kennedy et al., 2007) and Leber's congenital amaurosis (Baye et al., 2011), making zebrafish a model of choice for study of human retinal disorders.

\section{AUTHOR CONTRIBUTIONS}

$\mathrm{AM}, \mathrm{RN}$ and $\mathrm{VC}$ all contributed to writing the article and selection of figures. Supported by funds from the College of Arts and Science and the American University Library (to VPC).

Ahnelt, P., and Kolb, H. (1994). Horizontal cells and cone photoreceptors in primate retina: a Golgi-light microscopic study of spectral connectivity. J. Comp. Neurol. 343, 387-405. doi: 10.1002/cne.903430305

Allison, W. T., Barthel, L. K., Skebo, K. M., Takechi, M., Kawamura, S., and Raymond, P. A. (2010). Ontogeny of cone photoreceptor mosaics 
in zebrafish. J. Comp. Neurol. 518, 4182-4195. doi: 10.1002/cne. 22447

Allison, W. T., Haimberger, T. J., Hawryshyn, C. W., and Temple, S. E. (2004). Visual pigment composition in zebrafish: evidence for a rhodopsin-porphyropsin interchange system. Vis. Neurosci. 21, 945-952. doi: 10.1017/S0952523804216145

Allwardt, B. A., Lall, A. B., Brockerhoff, S. E., and Dowling, J. E. (2001). Synapse formation is arrested in retinal photoreceptors of the zebrafish nrc mutant. J. Neurosci. 21, 2330-2342. doi: 10.1523/jneurosci.21-07-02330.2001

Alvarez, Y., Chen, K., Reynolds, A. L., Waghorne, N., O'Connor, J. J., and Kennedy, B. N. (2010). Predominant cone photoreceptor dysfunction in a hyperglycaemic model of non-proliferative diabetic retinopathy. Dis. Model. Mech. 3, 236-245. doi: 10.1242/dmm.003772

Alvarez-Delfin, K., Morris, A. C., Snelson, C. D., Gamse, J. T., Gupta, T., Marlow, F. L., et al. (2009). Tbx2b is required for ultraviolet photoreceptor cell specification during zebrafish retinal development. Proc. Natl. Acad. Sci. US A 106, 2023-2038. doi: 10.1073/pnas.0809439106

Arenzana, F. J., Arévalo, R., Sánchez-González, R., Clemente, D., Aijón, J., and Porteros, A. (2006). Tyrosine hydroxylase immunoreactivity in the developing visual pathway of the zebrafish. Anat. Embryol. 211, 323-334. doi: 10.1007/s00429-006-0084-2

Asi, H., and Perlman, I. (1998). Neural interactions between cone photoreceptors and horizontal cells in the turtle (Mauremys caspica) retina. Vis. Neurosci. 15, 1-13. doi: 10.1017/s0952523898146047

Avdesh, A., Martin-Iverson, M. T., Mondal, A., Chen, M., Askraba, S., Morgan, N., et al. (2012). Evaluation of color preference in zebrafish for learning and memory. J. Alzheimers Dis. 28, 459-469. doi: 10.3233/JAD-2011-110704

Barnerias, C., Saudubray, J.-M., Touati, G., De Lonlay, P., Dulac, O., Ponsot, G., et al. (2010). Pyruvate dehydrogenase complex deficiency: four neurological phenotypes with differing pathogenesis. Dev. Med. Child Neurol. 52, e1-e9. doi: 10.1111/j.1469-8749.2009.03541.x

Bault, Z. A., Peterson, S. M., and Freeman, J. L. (2015). Directional and color preference in adult zebrafish: implications in behavioral and learning assays in neurotoxicology studies. J. Appl. Toxicol. 35, 1502-1510. doi: 10.1002/ja t.3169

Baye, L. M., Patrinostro, X., Swaminathan, S., Beck, J. S., Zhang, Y., Stone, E. M., et al. (2011). The N-terminal region of centrosomal protein 290 (CEP290) restores vision in a zebrafish model of human blindness. Human Mol. Gen. 20, 1467-1477. doi: 10.1093/hmg/ddr025

Bibliowicz, J., Tittle, R. K., and Gross, J. M. (2011). Towards a better understanding of human eye disease: insights from the zebrafish, Danio rerio. Prog. Mol. Biol. Transl. Sci. 100, 287-330. doi: 10.1016/B978-0-12-384878-9.00007-8

Bilotta, J., and Abramov, I. (1989). Spatiospectral properties of goldfish retinal ganglion cells. J. Neurophysiol. 62, 1140-1148. doi: 10.1152/jn.1989.62.5.1140

Bilotta, J., Saszik, S., and Sutherland, S. (2001). Rod contributions to the electroretinogram of the dark-adapted developing zebrafish. Dev. Dyn. 222, 564-570. doi: 10.1002/dvdy.1188

Bilotta, J., Trace, S. E., Vukmanic, E. V., and Risner, M. L. (2005). Ultraviolet- and short-wavelength cone contributions alter the early components of the ERG of young zebrafish. Int. J. Dev. Neurosci. 23, 15-25. doi: 10.1016/j.ijdevneu.2004. 09.004

Bowling, D. B. (1980). Light responses of ganglion cells in the retina of the turtle. J. Physiol. 299, 173-196. doi: 10.1113/jphysiol.1980.sp013118

Branchek, T. (1984). The development of photoreceptors in the zebrafish, Brachydanio rerio: II. Function. J. Comp. Neurol. 224, 116-122. doi: $10.1002 / \mathrm{cne} .902240110$

Branchek, T., and Bremiller, R. (1984). The development of photoreceptors in the zebrafish, Brachydanio rerio. I. Structure. J. Comp. Neurol. 224, 107-115. doi: 10.1002/cne.902240109

Brockerhoff, S. E., Dowling, J. E., and Hurley, J. B. (1998). Zebrafish retinal mutants. Vision Res. 38, 1335-1339. doi: 10.1016/s0042-6989(97)00227-7

Brockerhoff, S. E., and Fadool, J. M. (2011). Genetics of photoreceptor degeneration and regeneration in zebrafish. Cell. Moll. Life Sci. 68, 651-659. doi: 10.1007/s00018-010-0563-8

Brockerhoff, S. E., Hurley, J. B., Janssen-Bienhold, U., Neuhauss, S. C., Driever, W., and Dowling, J. E. (1995). A behavioral screen for isolating zebrafish mutants with visual system defects. Proc. Natl. Acad. Sci. U S A 92, 10545-10549. doi: $10.1073 /$ pnas.92.23.10545
Brockerhoff, S. E., Hurley, J. B., Niemi, G. A., and Dowling, J. E. (1997). A new form of inherited red-blindness identified in zebrafish. J. Neurosci. 17, 4236-4242. doi: 10.1523/jneurosci.17-11-04236.1997

Brockerhoff, S. E., Rieke, F., Matthews, H. R., Taylor, M. R., Kennedy, B., Ankoudinova, I., et al. (2003). Light stimulates a transducin-independent increase of cytoplasmic $\mathrm{Ca}^{2+}$ and suppression of current in cones from the zebrafish mutant nof. J. Neurosci. 23, 470-480. doi: 10.1523/jneurosci.23-0200470.2003

Burrill, J. D., and Easter, S. S. Jr. (1995). The first retinal axons and their microenvironment in zebrafish cryptic pioneers and the pretract. J. Neurosci. 15, 2935-2947. doi: 10.1523/jneurosci.15-04-02935.1995

Caldwell, J. H., and Daw, N. W. (1978). New properties of rabbit retinal ganglion cells. J. Physiol. 276, 257-276. doi: 10.1113/jphysiol.1978.sp012232

Calkins, D. J., Tsukamoto, Y., and Sterling, P. (1998). Microcircuitry and mosaic of a blue-yellow ganglion cell in the primate retina. J. Neurosci. 18, 3373-3385. doi: 10.1523/jneurosci.18-09-03373.1998

Cameron, D. A. (2002). Mapping absorbance spectra, cone fractions and neuronal mechanism to photopic spectral sensitivity in the zebrafish. Vis. Neurosci. 19, 365-372. doi: 10.1017/s0952523802192121

Carter-Dawson, L. D., and Lavail, M. M. (1979). Rods and cones in the mouse retina: II. Autoradiographic analysis of cell generation using tritiated thymidine. J. Comp. Neurol. 188, 263-272. doi: 10.1002/cne.9018 80205

Chang, L., Breuninger, T., and Euler, T. (2013). Chromatic coding from cone-type unselective circuits in the mouse retina. Neuron 77, 559-571. doi: 10.1016/j.neuron.2012.12.012

Chinen, A., Hamaoka, T., Yamada, Y., and Kawamura, S. (2003). Gene duplication and spectral diversification of cone visual pigments of zebrafish. Genetics 163, 663-675.

Colwill, R. M., Raymond, M. P., Ferreira, L., and Escudero, H. (2005). Visual discrimination learning in zebrafish (Danio rerio). Behav. Processes 70, 19-31. doi: 10.1016/j.beproc.2005.03.001

Connaughton, V. P. (2001). Organization of ON- and OFF-pathways in the zebrafish retina: neurotransmitter localization, electrophysiological responses of bipolar cells and patterns of axon terminal stratification. Prog. Brain Res. 131, 161-176. doi: 10.1016/s0079-6123(01)31014-2

Connaughton, V. P., Graham, D., and Nelson, R. (2004). Identification and morphological classification of horizontal, bipolar, and amacrine cells within the zebrafish retina. J. Comp. Neurol. 477, 371-385. doi: 10.1002/cne. 20261

Connaughton, V. P., and Nelson, R. (2000). Axonal stratification patterns and glutamate-gated conductance mechanisms in zebrafish retinal bipolar cells. J. Physiol. 524, 135-146. doi: 10.1111/j.1469-7793.2000.t01-1-00135.x

Connaughton, V. P., and Nelson, R. (2010). Spectral responses in zebrafish horizontal cells include a tetraphasic response and a novel UV-dominated triphasic response. J. Neurophysiol. 104, 2407-2422. doi: 10.1152/jn. 00644.2009

Connaughton, V. P., and Nelson, R. (2015). Ultraviolet dominates ganglion cell responses in larval zebrafish retinas. Invest. Ophthalmol. Vis. Sci. 56, 3251.

Crocker, R. A., Ringo, J., Wolbarsht, M. L., and Wagner, H. G. (1980). Cone contributions to cat retinal ganglion cell receptive fields. J. Gen. Physiol. 76, 763-785. doi: 10.1085/jgp.76.6.763

Crook, J. D., Davenport, C. M., Peterson, B. B., Packer, O. S., Detwiler, P. B., and Dacey, D. M. (2009). Parallel ON and OFF cone bipolar inputs establish spatially coextensive receptive field structure of blue-yellow ganglion cells in primate retina. J. Neurosci. 29, 8372-8387. doi: 10.1523/jneurosci.121809.2009

Dacey, D. M. (1999). Primate retina: cell types, circuits and color opponency. Prog. Retin Eye Res. 18, 737-763. doi: 10.1016/s1350-9462(98)00013-5

Dacey, D. M., Crook, J. D., and Packer, O. S. (2014). Distinct synaptic mechanisms create parallel S-ON and S-OFF color opponent pathways in the primate retina. Vis. Neurosci. 31, 139-151. doi: 10.1017/s0952523813000230

Dacey, D. M., Diller, L. C., Verweij, J., and Williams, D. R. (2000). Physiology of $\mathrm{L}-$ and M-cone inputs to $\mathrm{H} 1$ horizontal cells in the primate retina. J. Opt. Soc Am. A Opt. Image Sci. Vis. 17, 589-596. doi: 10.1364/josaa.17.000589

Dacey, D. M., and Lee, B. B. (1994). The 'blue-on' opponent pathway in primate retina originates from a distinct bistratified ganglion cell type. Nature 367, 731-735. doi: 10.1038/367731a0 
Dacey, D. M., Lee, B. B., Stafford, D. K., Pokomy, J., and Smith, V. C. (1996). Horizontal cells of the primate retina: cone specificity without spectral opponency. Science 271, 656-659. doi: 10.1126/science.271.5249.656

Dacheux, R. F., and Raviola, E. (1982). Horizontal cells in the retina of the rabbit. J. Neurosci. 2, 1486-1493. doi: 10.1523/jneurosci.02-10-01486.1982

Daw, N. W. (1968). Colour-coded ganglion cells in the goldfish retina: extension of their receptive fields by means of new stimuli. J. Physiol. 197, 567-592. doi: 10.1113/jphysiol.1968.sp008575

Daw, N. W., and Pearlman, A. L. (1970). Cat colour vision: evidence for more than one process. J. Physiol. 211, 125-137. doi: 10.1113/jphysiol.1970.sp009270

De Monasterio, F. M. (1978). Spectral interactions in horizontal and ganglion cells of the isolated and arterially-perfused rabbit retina. Brain Res. 150, 239-258. doi: 10.1016/0006-8993(78)90278-0

De Monasterio, F. M., and Gouras, P. (1975). Functional properties of ganglion cells of the rhesus monkey retina. J. Physiol. 251, 167-195. doi: 10.1113/jphysiol. 1975.sp011086

Djamgoz, M. B., Downing, J. E., Kirsch, M., Prince, D. J., and Wagner, H.-J. (1988). Plasticity of cone horizontal cell functioning in cyprinid fish retina: effects of background illumination of moderate intensity. J. Neurocytol. 17, 701-710. doi: 10.1007/bf01260997

Dreosti, E., Odermatt, B., Dorostkar, M. M., and Lagnado, L. (2009). A genetically encoded reporter of synaptic activity in vivo. Nat. Methods 6, 883-889. doi: $10.1038 /$ nmeth. 1399

Easter, S. S. Jr., and Nicola, G. N. (1996). The development of vision in the zebrafish (Danio rerio). Dev. Biol. 180, 646-663. doi: 10.1006/dbio.1996.0335

Easter, S. S. Jr., and Nicola, G. N. (1997). The development of eye movements in the zebrafish (Danio rerio). Dev. Psychobiol. 31, 267-276. doi: 10.1002/(sici)10982302(199712)31:4<267::aid-dev4>3.0.co;2-p

Emran, F., Rihel, J., Adolph, A., Wong, K., Kraves, S., and Dowling, J. (2007). OFF ganglion cells cannot drive the optokinetic reflex in zebrafish. Proc. Natl. Acad. Sci. U S A 104, 19126-19131. doi: 10.1073/pnas.0709337104

Emran, F., Rihel, J., and Dowling, J. E. (2008). A behavioral assay to measure responsiveness of zebrafish to changes in light intensities. J. Vis. Exp. 20:e923. doi: $10.3791 / 923$

Endeman, D., Klaassen, L. J., and Kamermans, M. (2013). Action spectra of zebrafish cone photoreceptors. PLoS One 8:e68540. doi: 10.1371/journal.pone. 0068540

Engström, K. (1960). Cone types and cone arrangement in the retina of some cyprinids. Acta Zoologica 41, 277-295. doi: 10.1111/j.1463-6395.1960.tb0 0481.x

Enright, J. M., Toomey, M. B., Sato, S.-Y., Temple, S. E., Allen, J. R., Fujiwara, R., et al. (2015). Cyp27c1 red-shifts the spectral sensitivity of photoreceptors by converting vitamin A1 into A2. Curr. Biol. 25, 3048-3057. doi: 10.1016/j.cub. 2015.10.018

Fadool, J. M. (2003). Development of a rod photoreceptor mosaic revealed in transgenic zebrafish. Dev. Biol. 258, 277-290. doi: 10.1016/s00121606(03)00125-8

Fisher, S. K., and Boycott, B. B. (1974). Synaptic connections made by horizontal cells within the outer plexiform layer of the retina of the cat and the rabbit. Proc. R. Soc. Lond. B Biol. Sci. 186, 317-331. doi: 10.1098/rspb.1974.0052

Fraser, B., Duval, M. G., Wang, H., and Allison, W. T. (2013). Regeneratino of cone photoreceptors when cell ablation is primarily restricted to a particular cone subtype. PLoS One 8:e55410. doi: 10.1371/journal.pone. 0055410

Gleeson, M., Connaughton, V., and Arneson, L. S. (2007). Induction of hyperglycemia in zebrafish, Danio rerio, leads to morphological changes in the retina. Acta Diabetol. 44, 157-163. doi: 10.1007/s00592-007-0257-3

Grant, G. B., and Dowling, J. E. (1995). A glutamate-activated chloride current in cone-driven ON-bipolar cells of the white perch retina. J. Neurosci. 15, 3852-3862. doi: 10.1523/jneurosci.15-05-03852.1995

Gross, J. M., and Perkins, B. D. (2008). Zebrafish mutants as models for congenital ocular disorders in humans. Mol. Reprod. Dev. 75, 547-555. doi: 10.1002/mrd. 20831

Guenther, E., and Zrenner, E. (1993). The spectral sensitivity of darkand light-adapted cat retinal ganglion cells. J. Neurosci. 13, 1543-1550. doi: 10.1523/jneurosci.13-04-01543.1993

Hagerman, G. F., Noell, N. C., Cao, S. Y., Duval, M. G., Oel, A. P., and Allison, W. T. (2016). Rapid recovery of visual function associated wtih blue cone ablation in zebrafish. PLoS One 11:e0166932. doi: 10.1371/journal.pone. 0166932

Haverkamp, S., Wassle, H., Duebel, J., Kuner, T., Augustine, G., Feng, G., et al. (2005). The primordial, blue-cone color system of the mouse retina. J. Neurosci. 25, 5438-5445. doi: 10.1523/jneurosci.1117-05.2005

Hemmi, J. M., James, A., and Taylor, W. R. (2002). Color opponent retinal ganglion cells in the tammar wallaby retina. J. Vis. 2, 608-617. doi: 10.1167/ 2.9 .3

Holzhausen, L. C., Lewis, A. A., Cheong, K. K., and Brockerhoff, S. E. (2009). Differential role of synaptojanin 1 in rod and cone photoreceptors. J. Comp. Neurol. 517, 633-644. doi: 10.1002/cne.22176

Hu, M., and Easter, S. S. (1999). Retinal neurogenesis: the formation of the initial central patch of postmitotic cells. Dev. Biol. 207, 309-321. doi: 10.1006/dbio. 1998.9031

Huang, L., Maaswinkel, H., and Li, L. (2005). Olfactoretinal centrifugal input modulates zebrafish retinal ganglion cell activity: a possibel role for dopamine-mediated $\mathrm{Ca}^{2+}$ signaling pathways. J. Physiol. 569, 939-948. doi: 10.1113/jphysiol.2005.099531

Huang, S. H., Pittler, S. J., Huang, X., Oliveira, L., Berson, E., and Dryja, T. P. (1995). Autosomal recessive retinitis pigmentose caused by mutations in the $\alpha$-subunit of rod cGMP phosphodiesterase. Nat. Genet. 11, 468-471. doi: 10.1038/ng1295-468

Hubbard, R., and Kropf, A. (1958). The action of ight on rhodopsin. Proc. Natl. Acad. Sci. U S A 44, 130-139. doi: 10.1073/pnas.44.2.130

Hughes, H., Saszik, S., Bilotta, J., Demarco, P., and Patterson, W. (1998). Cone contributions to the photopic spectral sensitivity of the zebrafish ERG. Vis. Neurosci. 15, 1029-1037. doi: 10.1017/s095252389815602x

Intine, R. V., Olsen, A. S., and Sarras, M. P. (2013). A zebrafish model of diabetes mellitus and metabolic memory. J. Vis. Exp. 72:e50232. doi: 10.3791/ 50232

Jang, Y.-J., Yu, S.-H., Lee, E.-S., and Jeon, C.-J. (2011). Two types of tyrosine hydroxylase-immunoreactive neurons in the zebrafish retina. Neurosci. Res. 71, 124-133. doi: 10.1016/j.neures.2011.07.002

Johnston, J., and Lagnado, L. (2012). What the fish's eye tells the fish's brain. Neuron 76, 257-259. doi: 10.1016/j.neuron.2012.10.006

Jusuf, P. R., Almeida, A. D., Randlett, O., Joubin, K., Poggi, L., and Harris, W. (2011). Origin and determination of inhibitory cell lineages in the vertebrate retina. J. Neurosci. 31, 2549-2562. doi: 10.1523/jneurosci.471310.2011

Jusuf, P. R., and Harris, W. A. (2009). Ptfla is expressed transiently in all types of amacrine cells in the embryonic zebrafish retina. Neural Dev. 4:34. doi: 10.1186/1749-8104-4-34

Kaneko, A. (1970). Physiological and morpholgical identification of horizontal, bipolar and amacrine cells in goldfish retina. J. Physiol. 207, 623-633. doi: 10.1113/jphysiol.1970.sp009084

Kaneko, A. (1973). Receptive field organization of bipolar and amacrine cells in the goldfish retina. J. Physiol. 235, 133-153. doi: 10.1113/jphysiol.1973.sp010381

Karp, G. (1999). Cell and Molecular Biology. New York, NY: John Wiley \& Sons, Inc.

Kay, J. N., Finger-Baier, K. C., Roeser, T., Staub, W., and Baier, H. (2001). Retinal ganglion cell genesis required lakritz, a zebrafish atonal homolog. Neuron 30 , 725-736. doi: 10.1016/s0896-6273(01)00312-9

Kennedy, B. N., Alvarez, Y., Brockerhoff, S. E., Stearns, G. W., Sapetto-Rebow, B., Taylor, M. R., et al. (2007). Identification of a zebrafish cone photoreceptorspecific promoter and genetic rescue of achromatopsia in the nof mutant. Invest. Ophthalmol. Vis. Sci. 48, 522-529. doi: 10.1167/iovs.06-0975

Kljavin, I. (1987). Early development of photoreceptors in the ventral retina of the zebrafish embryo. J. Comp. Neurol. 260, 461-471. doi: 10.1002/cne.9026 00311

Kolb, H. (1970). Organization of the outer plexiform layer of the primate retina: electron microscopy of Golgi-impregnated cells. Philos. Trans. R. Soc. Lond. B Biol. Sci. 258, 261-283. doi: 10.1098/rstb.1970.0036

Kolb, H. (1977). The organization of the outer plexiform layer in the retina of the cat: electron microscopic observations. J. Neurocytol. 6, 131-153. doi: 10.1007/bf01261502

Kolb, H., and Famiglietti, E. V. (1974). Rod and cone pathways in the inner plexiform layer of cat retina. Science 186, 47-49. doi: 10.1126/science.186. 4158.47 
Kolb, H., Nelson, R., and Mariani, A. (1981). Amacrine cells, bipolar cells and ganglion cells of the cat retina: a Golgi study. Vision Res. 21, 1081-1114. doi: 10.1016/0042-6989(81)90013-4

Krauss, A., and Neumeyer, C. (2003). Wavelenght dependence of the optomotor response in zebrafish (Danio rerio). Vision Res. 43, 1275-1282. doi: 10.1016/s0042-6989(03)00090-7

Larison, K. D., and Bremiller, R. (1990). Early onset of phenotype and cell patterning in the embryonic zebrafish retina. Development 109, 567-576.

Lee, B. B., and Sun, H. (2009). The chromatic input to cells of the magnocellular pathway of primates. J. Vis. 9, 1-18. doi: 10.1167/9.2.15

Lewis, A. A., Mahoney, J. T., Wilson, N., and Brockerhoff, S. E. (2015). Identification of amacrine subtypes that express the atypical cadherin celsr3. Exp. Eye Res. 130, 51-57. doi: 10.1016/j.exer.2014.12.003

Li, L., and Dowling, J. E. (1997). A dominant form of inherited retinal degeneration caused by a non-photoreceptor cell-specific mutation. Proc. Natl. Acad. Sci. U S A 94, 11645-11650. doi: 10.1073/pnas.94.21.11645

Li, L., and Dowling, J. E. (2000). Effects of dopamine depletion on visual sensitivity of zebrafish. J. Neurosci. 20, 1893-1903. doi: 10.1523/jneurosci.20-05-0189 3.2000

Li, Y. N., Matsui, J. I., and Dowling, J. E. (2009). Specificity of the horizontal cell-photoreceptor connections in the zebrafish (Danio rerio) retina. J. Comp. Neurol. 516, 442-453. doi: 10.1002/cne.22135

Li, Y. X., Schaffner, A. E., Walton, M. K., and Barker, J. L. (1998). Astrocytes regulate developmental changes in the chloride ion gradient of embronic rat ventral spinal cord neurons in culture. J. Physiol. 509, 847-858. doi: 10.1111/j. 1469-7793.1998.847bm.x

Li, Y. X., Tsujimura, T., Kawamura, S., and Dowling, J. E. (2012). Bipolar cell-photoreceptor connectivity in the zebrafish (Danio rerio) retina. J. Comp. Neurol. 520, 3786-3802. doi: 10.1002/cne.23168

Link, B. A., and Collery, R. F. (2015). Zebrafish models of retinal disease. Annu. Rev. Vis. Sci. 1, 125-153. doi: 10.1146/annurev-vision-082114-035717

Mackintosh, R. M., Bilotta, J., and Abramov, I. (1987). Contributions of shortwavelength cones to goldfish ganglion cells. J. Comp. Physiol. A 161, 85-94. doi: $10.1007 / \mathrm{bf} 00609457$

MacNeil, M. A., Heussy, J. K., Dacheux, R. F., Raviola, E., and Masland, R. H. (1999). The shapes and numbers of amacrine cells: matching of photofilled with Golgi-stained cells in the rabbit retina and comparison with other mammalian species. J. Comp. Neurol. 413, 305-326. doi: 10.1002/(sici)10969861(19991018)413:2<305::aid-cne10>3.0.co;2-e

Mangrum, W. I., Dowling, J. E., and Cohen, E. D. (2002). A morphological classification of ganglion cells in the zebrafish retina. Vis. Neurosci. 19, 767-779. doi: $10.1017 / \mathrm{s} 0952523802196076$

Marc, R., and Cameron, D. (2001). A molecular phenotype atlas of the zebrafish retina. J. Neurocytol. 30, 593-654. doi: 10.1023/A:1016516818393

Mariani, A. P. (1984). Bipolar cells in monkey retina selective for the cones likely to be blue-sensitive. Nature 308, 184-186. doi: 10.1038/308184a0

Marshak, D. W., and Mills, S. L. (2014). Short-wavelength cone-opponent retinal ganglion cells in mammals. Vis. Neurosci. 31, 165-175. doi: $10.1017 / \mathrm{s} 095252381300031 \mathrm{x}$

Masland, R. H. (2012). The neuronal organization of the retina. Neuron 76, 266-280. doi: 10.1016/j.neuron.2012.10.002

McDowell, A. L., Dixon, L. J., Houchins, J. D., and Bilotta, J. (2004). Visual processing of the zebrafish optic tectum before and after optic nerve damage. Vis. Neurosci. 21, 97-106. doi: 10.1017/s0952523804043019

Menger, N., and Wässle, H. (2000). Morphological and physiological properties of the A17 amacrine cell of the rat retina. Vis. Neurosci. 17, 769-780. doi: $10.1017 / \mathrm{s} 0952523800175108$

Miller, R. F., Staff, N. P., and Velte, T. J. (2006). Form and function of ON-OFF amacrine cells in the amphibian retina. J. Neurophysiol. 95, 3171-3190. doi: 10.1152/jn.00090.2005

Mills, S. L., Tian, L.-M., Hoshi, H., Whitaker, C. M., and Massey, S. C. (2014). Three distinct blue-green color pathways in a mammalian retina. J. Neurosci. 34, 1760-1768. doi: 10.1523/JNEUROSCI.3901-13.2014

Morris, A. C., and Fadool, J. M. (2005). Studying rod photroeceptor development in zebrafish. Physiol. Behav. 86, 306-313. doi: 10.1016/j.physbeh.2005. 08.020

Mumm, J. S., Williams, P. R., Godinho, L., Koerber, A., Pittman, A. J., Roeser, T., et al. (2006). In vivo imaging reveals dendritic targeting of laminated afferents by zebrafish retinal ganglion cells. Neuron 52, 609-621. doi: 10.1016/j.neuron. 2006.10.004

Naka, K. I., and Rushton, W. A. (1966a). S-potentials from colour units in the retina of fish (Cyprinidae). J. Physiol. 185, 536-555. doi: 10.1113/jphysiol.1966. sp008001

Naka, K. I., and Rushton, W. A. (1966b). S-potentials from luminosity units in the retina of fish (Cyprinidae). J. Physiol. 185, 587-599. doi: 10.1113/jphysiol.1966. sp008003

Nawrocki, L. W. (1985). Development of the Neural Retina in the Zebrafish, Brachydanio Rerio. PhD. Thesis. Eugene, OR: University of Oregon.

Negishi, K., Salas, R., Parthe, V., and Drujan, B. D. (1988). Identification of horizontal cells generating different spectral responses in the retina of a teleost fish (Eugerres plumieri). J. Neurosci. Res. 20, 246-256. doi: 10.1002/jnr. 490200214

Nelson, R. (1977). Cat cones have rod input: a comparison of the response properties of cones and horizontal cell bodies in the retina of the cat. J. Comp. Neurol. 172, 109-136. doi: 10.1002/cne.901720106

Nelson, R. (1982). AII amacrine cells quicken time course of rod signals in the cat retina. J. Neurophysiol. 47, 928-947. doi: 10.1152/jn.1982.47.5.928

Nelson, R. (1985). Spectral properties of cat horizontal cells. Neurosci. Res. Suppl. 2, S167-S183. doi: 10.1016/0921-8696(85)90015-5

Nelson, R., and Kolb, H. (1985). A17: a broad-field amacrine cell in the rod system of the cat retina. J. Neurophysiol. 54, 592-614. doi: 10.1152/jn.1985.54.3.592

Nelson, R. F., and Singla, N. (2009). A spectral model for signal elements isolated from zebrafish photopic electroretinogram. Vis. Neurosci. 26, 349-363. doi: 10.1017/s0952523809990113

Nelson, R., von Lutzow, A., Kolb, H., and Gouras, P. (1975). Horizontal cells in cat retina with independent dendritic systems. Science 189, 137-139. doi: $10.1126 /$ science. 1138370

Neuhauss, S. C. (2003). Behavioral genetic approaches to visual system development and function in zebrafish. J. Neurobiol. 54, 146-160. doi: 10.1002/ neu. 10165

Ng, L., Hurley, J. B., Dierks, B., Srinivas, M., Saltó, C., Vennström, B., et al. (2001). A thyroid hormone receptor that is required for the development of green cone photoreceptors. Nat. Genet. 27, 94-98. doi: 10.1038/83829

Niell, C. M., and Smith, S. J. (2005). Functional imaging reveals rapid development of visual response properties in the zebrafish tectum. Neuron 45, 941-951. doi: 10.1016/j.neuron.2005.01.047

Nishiwaki, Y., Komori, A., Sagara, H., Suzuki, E., Manabe, T., Hosoya, T., et al. (2008). Mutation of cGMP phosphodiesterase-6 $\alpha /$-subunit gene causes progressive degeneration of cone photoreceptors in zebrafish. Mech. Dev. 125, 932-946. doi: 10.1016/j.mod.2008.09.001

Ogawa, Y., Shiraki, T., Kojima, D., and Fukada, Y. (2015). Homeobox transcription factor Six7 governs expression of green opsin genes in zebrafish. Proc. R. Soc. B Biol. Sci. 282:20150659. doi: 10.1098/rspb.2015.0659

Oliveira, J., Silveira, M., Chacon, D., and Luchiari, A. (2015). The zebrafish world of colors and shapes: preference and discrimination. Zebrafish 12, 166-173. doi: 10.1089/zeb.2014.1019

Olsen, A. S., Sarras, M. P. Jr., and Intine, R. V. (2010). Limb regeneration is impaired in an adult zebrafish model of diabetes mellitus. Wound Repair. Regen. 18, 532-542. doi: 10.1111/j.1524-475x.2010.00613.x

Orger, M. B., and Baier, H. (2005). Channeling of red and green cone inputs to the zebrafish optomotor response. Vis. Neurosci. 22, 275-281. doi: $10.1017 / \mathrm{s} 0952523805223039$

Pang, J.-J., Gao, F., and Wu, S. M. (2002). Segregation and integration of visual channels: layer-by-layer computation of ON-OFF signals by amacrine cell dendrites. J. Neurosci. 22, 4693-4701. doi: 10.1523/JNEUROSCI.22-11-0469 3.2002

Park, J.-S., Tyu, J.-H., Choi, T.-I., Bae, Y.-K., Lee, S., Kang, H., et al. (2016). Innate color preference of zebrafish and its use in behavioral analysis. Mol. Cells 39, 750-755. doi: 10.14348/molcells.2016.0173

Patel, K. P., O’Brien, T. W., Subramony, S. H., Shuster, J., and Stacpoole, P. W. (2012). the spectrum of pyruvate dehydrogenase complex deficiency: clinical, biochemical and genetic features in 371 patients. Mol. Genet. Metab. 106, 385-394. doi: 10.1016/j.ymgme.2011.09.032

Peeters, B. W., Mesokops, M., and Veenvliet, A. R. (2016). Color preference in Danio rerio: effects of age and anxiolytic treatments. Zebrafish 13, 330-334. doi: $10.1089 /$ zeb.2015.1150 
Peichl, L., and González-Soreiano, J. (1994). Morphological types of horizontal cell in rodent retinae: a comparison of rat, mouse, gerbil, and guinea pig. Vis. Neurosci. 11, 501-517. doi: 10.1017/s095252380000242x

Perera, R. M., Zoncu, R., Lucast, L., De Camilli, P., and Toomre, D. (2006). Two synaptojanin 1 isoforms are recruited to clathrin-coated pits at different stages. Proc. Natl. Acad. Sci. U S A. 103, 19332-19337. doi: 10.1073/pnas.0609795104

Pittler, S. J., and Baehr, W. (1991). Identification of a nonsense mutation in the rod photoreceptorcGMP phosphodiesterase B-subunit of the rd mouse. Proc. Natl. Acad. Sci. U S A 88, 8322-8326. doi: 10.1073/pnas.88.19.8322

Raymond, P. A., and Barthel, L. K. (2004). A moving wave patterns the cone photoreceptor mosaic array in the zebrafish retina. Int. J. Dev. Biol. 48, 935-945. doi: $10.1387 / \mathrm{ijdb} .041873 \mathrm{pr}$

Raymond, P. A., Barthel, L. K., and Curran, G. A. (1995). Developmental patterning of rod and cone photoreceptors in embryonic zebrafish. J. Comp. Neurol. 359, 537-550. doi: 10.1002/cne.903590403

Raymond, P. A., Barthel, L. K., Rounsifer, M. E., Sullivan, S. A., and Knight, J. K. (1993). Expression of rod and cone visual pigments in goldfish and zebrafish: a rhodopsin-like gene is expressed in cones. Neuron 10, 1161-1174. doi: 10.1016/0896-6273(93)90064-x

Raynauld, J.-P. (1972). Goldfish retina: sign of the rod input in opponent color ganglion cells. Science 177, 84-85. doi: 10.1126/science.177.4043.84

Risner, M. L., Lemerise, E., Vukmanic, E. V., and Moore, A. (2006). Behavioral spectral sensitivity of the zebrafish (Danio rerio). Vision Res. 46, 2625-2635. doi: 10.1016/j.visres.2005.12.014

Robinson, J., Schmitt, E. A., and Dowling, J. E. (1995). Temporal and spatial patterns of opsin gene expression in zebrafish (Danio rerio). Vis. Neurosci. 12, 895-906. doi: 10.1017/s0952523800009457

Robinson, J., Schmitt, E. A., Hárosi, F. I., Reece, R. J., and Dowling, J. E. (1993). Zebrafish ultraviolet visual pigment: absorption spectrum, sequence, and localization. Proc. Natl. Acad. Sci. U S A 90, 6009-6012. doi: 10.1073/pnas. 90.13.6009

Rocha, F. A., Saito, C. A., Silveira, L. C., de Souza, J. M., and Ventura, D. F. (2008). Twelve chromatically opponent ganglion cell types in turtle retina. Vis. Neurosci. 25, 307-315. doi: 10.1017/s0952523808080516

Rodieck, R. (1998). The First Steps in Seeing. Sunderland, MA: Sinauer Associates, Inc.

Rosa, J. M., Ruehle, S., Ding, H., and Lagnado, L. (2016). Crossover inhibition generates sustained visual responses in the inner retina. Neuron 90, 308-319. doi: 10.1016/j.neuron.2016.03.015

Saari, J. C. (2012). Vitamin A metabolism in rod and cone visual cycles. Annu. Rev. Nutr. 32, 125-145. doi: 10.1146/annurev-nutr-071811-150748

Sakai, H. M., Machuca, H., Korenberg, M. J., and Naka, K.-I. (1997). Processing of color- and noncolor-coded signals in the gourami retina: III. ganglion cells. J. Neurophysiol. 78, 2034-2047. doi: 10.1152/jn.1997.78.4.2034

Sanes, J. R., and Masland, R. H. (2015). The types of retinal ganglion cells: current status and implications for neuronal classification. Annu. Rev. Neurosci. 38, 221-246. doi: 10.1146/annurev-neuro-071714-034120

Saszik, S., Alexander, A., Lawrence, T., and Bilotta, J. (2002). APB differentially affects the cone contributions to the zebrafish ERG. Vis. Neurosci. 19, 521-529. doi: $10.1017 / \mathrm{s} 0952523802194144$

Saszik, S., Bilotta, J., and Givin, C. M. (1999). ERG assessment of zebrafish retinal development. Vis. Neurosci. 16, 881-888. doi: 10.1017/s0952523899 165076

Schmitt, E. A., and Dowling, J. E. (1994). Early-eye morphogenesis in the zebrafish, Brachydanio rerio. J. Comp. Neurol. 344, 532-542. doi: 10.1002/cne.903440404

Schmitt, E. A., and Dowling, J. E. (1999). Early retinal development in the zebrafish, Danio rerio: light and electron microscopic analysis. J. Comp. Neurol. 404, 515-536. doi: 10.1002/(sici)1096-9861(19990222)404:4<515::aid-cne8>3. $0 . \operatorname{co} ; 2-\mathrm{a}$

Shen, Y. C., and Raymond, P. A. (2004). Zebrafish cone-rod (crx) homeobox gene promotes retinogenesis. Dev. Biol. 269, 237-251. doi: 10.1016/j.ydbio.2004. 01.037

Sherry, D. M., and Yazulla, S. (1993). Goldfish bipolar cells and axon terminal patterns: a Golgi study. J. Comp. Neurol. 329, 188-200. doi: 10.1002/cne. 903290204

Silveira, L. C., Saito, C. A., Da Dilva Filho, M., Kremers, J., Bowmaker, J. K., and Lee, B. B. (2014). Alouatta trichomatic color vision: cone spectra and physiological responses studied with microspectrophotometry and single unit retinal electrophysiology. PLoS One 9:e113321. doi: 10.1371/journal.pone. 0113321

Siminoff, R. (1986). Dynamics of chromaticity horizontal cells in the freshwater turtle retina. Biol. Cybern. 54, 269-279. doi: 10.1007/bf00318423

Song, P. I., Matsui, J. I., and Dowling, J. E. (2008). Morphological types and connectivity of horizontal cells found in the adult zebrafish (Danio rerio) retina. J. Comp. Neurol. 506, 328-338. doi: 10.1002/cne.21549

Spekreijse, H., Wagner, H. G., and Wolbarsht, M. L. (1972). Spectral and spatial coding of ganglion cell responses in goldfish retina. J. Neurophysiol. 35, 73-86. doi: $10.1152 /$ jn.1972.35.1.73

Spence, R., and Smith, C. (2008). Innate and learned colour preference in the zebrafish, Danio rerio. Ethology 114, 582-588. doi: 10.1111/j.1439-0310.2008. 01515.x

Stafford, D. K., and Dacey, D. M. (1997). Physiology of the Al amacrine: a spiking, axon-bearing interneuron of the macaque monkey retina. Visual Neurosci. 14 507-522. doi: 10.1017/s0952523800012165

Stearns, G., Evangelista, M., Fadool, J. M., and Brockerhoff, S. E. (2007). A mutation in cone-specific pde6 gene causes rapid cone photoreceptor degeneration in zebrafish. J. Neurosci. 27, 13866-13874. doi: 10.1523/ JNEUROSCI.3136-07.2007

Steinberg, R. H. (1969). Rod and cone contributions to S-potentials from the cat retina. Vision Res. 9, 1319-1329. doi: 10.1016/0042-6989(69)90069-8

Stell, W. K. (1967). The structure and relationships of horizontal cells and photoreceptor-bipolar synaptic complexes in goldfish retina. Am. J. Anat. 121, 401-423. doi: 10.1002/aja.1001210213

Stell, W. K. (1975). Horizontal cell axons and axon terminals in goldfish retina. J. Comp. Neurol. 159, 503-519. doi: 10.1002/cne.901590405

Stell, W. K., and Lightfoot, D. O. (1975). Color-specific interconnections of cones and horizontal cells in the retina of the goldfish. J. Comp. Neurol. 159, 473-501. doi: 10.1002/cne.901590404

Stuermer, C. A. (1988). Retinotopic organization of the developing retinotectal projection in the zebrafish embryo. J. Neurosci. 8, 4513-4530. doi: 10.1523/JNEUROSCI.08-12-04513.1988

Sun, W., Li, N., and He, S. (2002). Large-scale morphological survey of mouse retinal ganglion cells. J. Comp. Neurol. 451, 115-126. doi: 10.1002/cne.10323

Sun, H., Smithson, H. Z., Zaidi, Q., and Lee, B. B. (2006). Specificity of cone inputs to macaque retinal ganglion cells. J. Neurophysiol. 95, 837-849. doi: 10.1152/jn. 00714.2005

Suzuki, S. C., Bleckert, A., Williams, P. R., Takechi, M., Kawamura, S., and Wong, R. O. (2013). Cone photoreceptor types in zebrafish are generated by symmetric terminal divisions of dedicated precursors. Proc. Natl. Acad. Sci. U $S$ A 110, 15109-15114. doi: 10.1073/pnas.1303551110

Svaetichin, G., and Macnichol, E. F. Jr. (1958). Retinal mechanisms for chromatic and achromatic vision. Ann. N Y Acad. Sci. 74, 385-404. doi: 10.1111/j.17496632.1958.tb39560.x

Takechi, M., and Kawamura, S. (2005). Temporal and spatial changes in the expression pattern of multiple red and green subtype opsin genes during zebrafish development. J. Exp. Biol. 208, 1337-1345. doi: 10.1242/jeb.01532

Taylor, M. R., Hurley, J. B., Van Epps, H. A., and Brockerhoff, S. E. (2004). A zebrafish model for pyruvate dehydrogenase deficiency: rescue of neurological dysfunction and embryonic lethality using a ketogenic diet. Proc. Natl. Acad. Sci. U S A 101, 4584-4589. doi: 10.1073/pnas.0307074101

Taylor, M. R., Kikkawa, S., Diez-Juan, A., Ramamurthy, V., Kawakami, K., Carmeliet, P., et al. (2005). The zebrafish pob gene encodes a novel proetin required for survival of red cone photoreceptor cells. Genetics 170, 263-273. doi: 10.1534/genetics.104.036434

Torvund, M. M., Ma, T. S., Connaughton, V. P., Ono, F., and Nelson, R. F. (2017). Cone signals in the monostratified and bistratified amacrine cells of adult zebrafish retina. J. Comp. Neurol. 525, 1532-1557. doi: 10.1002/cne.24107

Tsang, S. H., Gouras, P., Yamashita, C. K., Kjeldbye, H., Fisher, J., Barber, D. B., et al. (1996). Retinal degeneration in mice lacking the $\gamma$-subunit of the rod cGMP phosphodiesterase. Science 272, 1026-1029. doi: 10.1126/science.272. 5264.1026

Twig, G., and Perlman, I. (2004). Homogeneity and diversity of color-opponent horizontal cells in the turtle retina: consequences for potential wavelength discrimination. J. Vis. 4, 403-414. doi: 10.1167/4.5.5

Van Dijk, B. W., and Spekreijse, H. (1984). Linear color opponency in carp retinal ganglion cells. Vision Res. 24, 1865-1872. doi: 10.1016/0042-6989(84)90019-1 
Van Epps, H. A., Hayashi, M., Lucast, L., Stearns, G. W., Hurley, J. B., De Camilli, P., et al. (2004). The zebrafish nrc mutant reveals a role for the polyphosphoinositide phosphatase synaptojanin 1 in cone photoreceptor ribbon anchoring. J. Neurosci. 24, 8641-8650. doi: 10.1523/JNEUROSCI.289204.2004

Van Epps, H. A., Yim, C. M., Hurley, J. B., and Brockerhoff, S. E. (2001). Investigations of photoreceptor synaptic transmission and light adaptation in the zebrafish visual mutant nrc. Invest. Ophthalmol. Vis. Sci. 42, 868-874.

Wagner, H. G., Macnichol, E. F., and Wolbarsht, M. L. (1960). The response properties of single ganglion cells in the goldfish retina. J. Gen. Physiol. 43, 45-62. doi: 10.1085/jgp.43.6.45

Wagner, H. G., and Wagner, E. (1988). Amacrine cells in the retina of a teleost fish, the roach (Rutilus rutilus): a Golgi study on differentiation and layering. Philos. Trans. R. Soc. Lond. B Biol. Sci. 321, 263-324. doi: 10.1098/rstb.1988.0094

Weiler, R. (1978). Horizontal cells of the carp retina: Golgi impregnation and Procion-Yellow injection. Cell Tissue Res. 195, 515-526. doi: 10.1007/bf002 33893

Wersinger, E., Schwab, Y., Sahel, J., Rendon, A., Pow, D., Picaud, S., et al. (2006). The glutamate transporter EAAT5 works as a presynaptic receptor in mouse rod bipolar cells. J. Physiol. 557, 221-234. doi: 10.1113/jphysiol.2006.118281

Witkovsky, P. (1965). The spectral sensitivity of retinal ganglion cells in the carp. Vision Res. 5, 603-614. doi: 10.1016/0042-6989(65)90034-9

Wong, K. Y., Cohen, E. D., and Dowling, J. E. (2005). Retinal bipolar cell input mechanisms in giant danio: II. Patch-clamp analysis of on bipolar cells. J. Neurophysiol. 93, 94-107. doi: 10.1152/jn.00270.2004

Wong, K. Y., and Dowling, J. E. (2005). Retinal bipolar cell input mechanisms in giant danio. III. ON-OFF bipolar cells and their color-opponent mechanisms. J. Neurophysiol. 94, 265-272. doi: 10.1152/jn.00271.2004

Wu, S. M., Gao, F., and Maple, B. R. (2000). Functional architecture of synapses in the inner retina: segregation of visual signals by stratification of bipolar cell axon terminals. J. Neurosci. 20, 4462-4470. doi: 10.1523/JNEUROSCI.20-1204462.2000

Yang, X.-L., Tauchi, M., and Kaneko, A. (1983). Convergenece of signals from red-sensitive and green-sensitive cones onto L-type external horizontal cells of the goldfish retina. Vision Res. 23, 371-380. doi: 10.1016/0042-6989(83) 90084-6

Yazulla, S., and Studholme, K. M. (2001). Neurochemical anatomy of the zebrafish retina as determined by immunocytochemistry. J. Neurocytol. 30, 551-592. doi: 10.1023/A:1016512617484

Yeo, J.-Y., Lee, E.-S., and Jeon, C.-J. (2009). Parvalbumin-immunoreactive neurons in the inner nuclear layer of zebrafish retina. Exp. Eye Res. 88, 553-560. doi: 10.1016/j.exer.2008.11.014
Yin, L., Smith, R. G., Sterling, P., and Brainard, D. H. (2006). Chromatic properties of horizontal and ganglion cell responses follow a dual gradient in cone opsin expression. J. Neurosci. 26, 12351-12361. doi: 10.1523/JNEUROSCI.107106.2006

Yin, L., Smith, R. G., Sterling, P., and Brainard, D. H. (2009). Physiology and morphology of color-opponent ganglion cells in a retina expressing a dual gradient of $\mathrm{S}$ and $\mathrm{M}$ opsins. J. Neurosci. 29, 2706-2724. doi: 10.1523/JNEUROSCI.5471-08.2009

Yoshimatsu, T., Williams, P. R., D’Orazi, F. D., Suzuki, S. C., Fadool, J. M., Allison, W., et al. (2014). Transmission from the dominant input shapes the stereotypic ratio of photoreceptor inputs onto horizontal cells. Nat. Commun. 5:3699. doi: 10.1038/ncomms4699

Zhang, R.-W., Wei, H.-P., Xia, Y.-M., and Du, J.-L. (2010). Development of light response and GABAergic excitation-to-inhibition switch in zebrafish retinal ganglion cells. J. Physiol. 588, 2557-2569. doi: 10.1113/jphysiol.2010. 187088

Zhang, A.-J., and Wu, S. M. (2010). Responses and receptive fields of amacrine cells and ganglion cells in the salamander retina. Vision Res. 50, 614-622. doi: 10.1016/j.visres.2010.01.009

Zhou, Y., Chen, A.-H., Gong, H.-Q., and Liang, P.-J. (2005). Color information encoded by the spatiotemporal patterns of light response in ganglion cells of chick retina. Brain Res. 1059, 1-6. doi: 10.1016/j.brainres.2005. 07.077

Zimmermann, M. J. Y., Nevala, N. E., Yoshimatsu, T., Osorio, D., Nilsson, D.E., Berns, P., et al. (2018). Zebrafish differentially process colour across visual space to match natural scenes. Curr. Biol. 28, 2018.e5-2032.e5. doi: 10.1016/j. cub.2018.04.075

Zrenner, E., Nelson, R., and Mariani, A. (1983). Intracellular ercordings from a biplexiform ganglion cell in macaque retina, stained with horseradish peroxidase. Brain Res. 262, 181-185. doi: 10.1016/0006-8993(83)91007-7

Conflict of Interest Statement: The authors declare that the research was conducted in the absence of any commercial or financial relationships that could be construed as a potential conflict of interest.

Copyright (c) 2018 Meier, Nelson and Connaughton. This is an open-access article distributed under the terms of the Creative Commons Attribution License (CC BY). The use, distribution or reproduction in other forums is permitted, provided the original author(s) and the copyright owner(s) are credited and that the original publication in this journal is cited, in accordance with accepted academic practice. No use, distribution or reproduction is permitted which does not comply with these terms. 